\title{
Methane dynamics in an estuarine brackish Cyperus malaccensis marsh: Production and porewater concentration in soils, and net emissions to the atmosphere over five years
}

P. Yang, M. H. Wang, Derrick Y. F. Lai, K. P. Chun, J. F. Huang, S. A. Wan, David Bastviken and C. Tong

The self-archived postprint version of this journal article is available at Linköping University Institutional Repository (DiVA):

http://urn.kb.se/resolve?urn=urn:nbn:se:liu:diva-154540

N.B.: When citing this work, cite the original publication.

Yang, P., Wang, M. H., Lai, D. Y. F., Chun, K. P., Huang, J. F., Wan, S. A., Bastviken, D., Tong, C., (2019), Methane dynamics in an estuarine brackish Cyperus malaccensis marsh: Production and porewater concentration in soils, and net emissions to the atmosphere over five years, Geoderma, 337, 132-142. https://doi.org/10.1016/j.geoderma.2018.09.019

Original publication available at:

https://doi.org/10.1016/j.geoderma.2018.09.019

Copyright: Elsevier

http://www.elsevier.com/

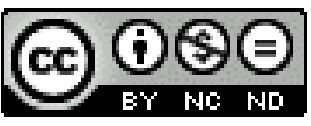




\section{H I G H L I G H T S}

- Coastal marsh $\mathrm{CH}_{4}$ emissions had strong inter-annual and seasonal variability.

- High $\mathrm{CH}_{4}$ emissions were accompanied by high $\mathrm{CH}_{4}$ production and porewater $\mathrm{CH}_{4}$ concentrations.

- Brackish marshes in subtropical estuaries were important sources of $\mathrm{CH}_{4}$.

- Temperature, precipitation and salinity were the best predictors of $\mathrm{CH}_{4}$ emissions 


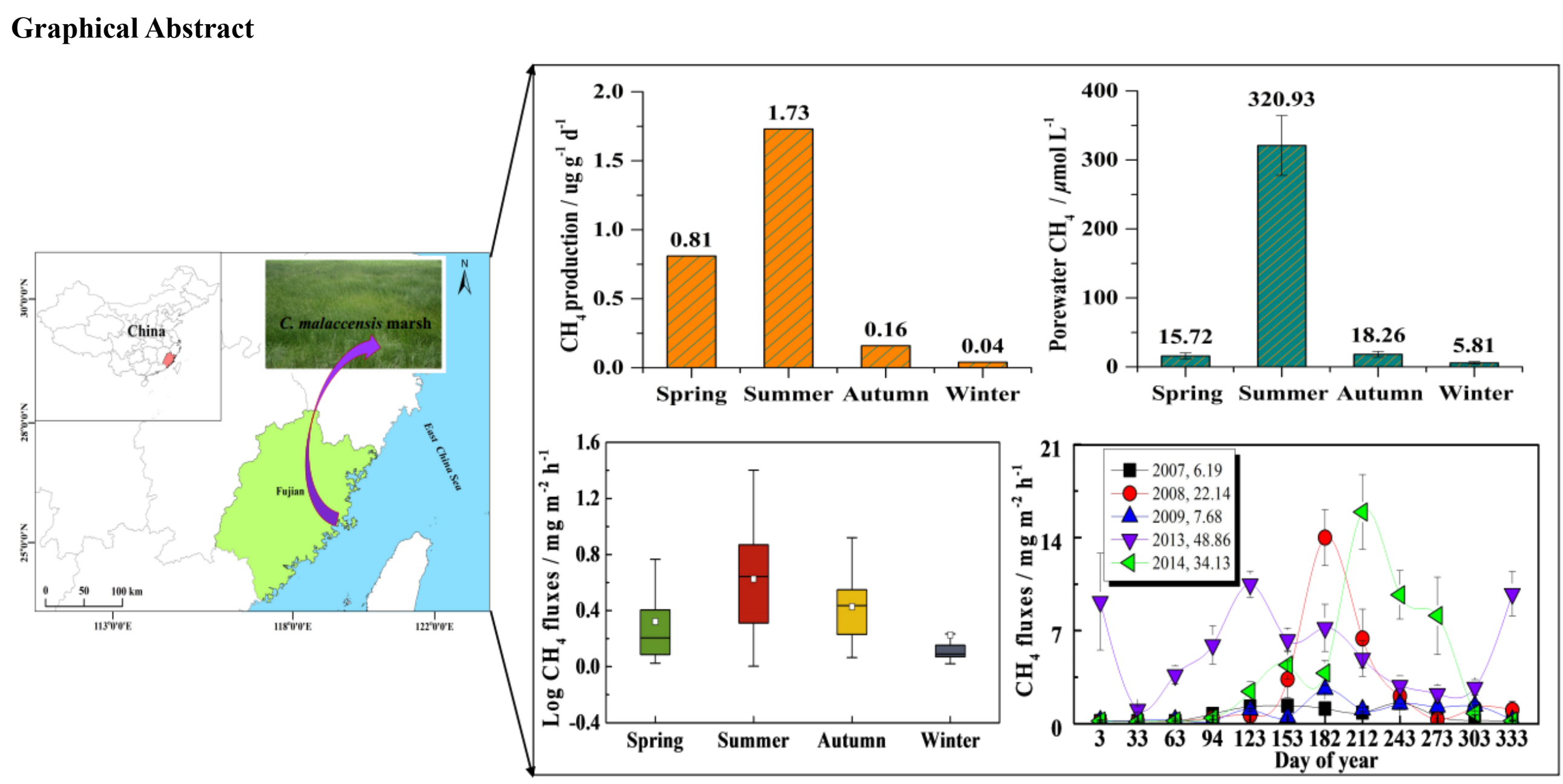




\section{Methane dynamics in an estuarine brackish Cyperus malaccensis marsh: Production and porewater concentration in soils, and net emissions to the atmosphere over five years}

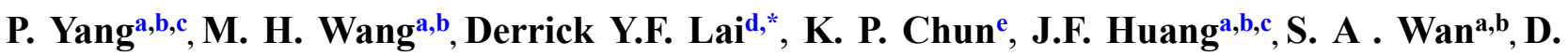
Bastviken, C . Tong ${ }^{\mathrm{a}, \mathrm{b}, \mathrm{c}, *}$

${ }^{a}$ Key Laboratory of Humid Sub-tropical Eco-geographical Process of Ministry of Education of China, Fujian Normal University, Fuzhou, China

${ }^{\mathrm{b}}$ School of Geographical Sciences, Fujian Normal University, Fuzhou, China

${ }^{\mathrm{c}}$ Research Centre of Wetlands in Subtropical Region, Fujian Normal University, Fuzhou, China

d Department of Geography and Resource Management, The Chinese University of Hong Kong, Shatin, New Territories, Hong Kong SAR, China

e Department of Geography, Hong Kong Baptist University, Kowloon Tong, Hong Kong, China ${ }^{\mathrm{f} D e p a r t m e n t}$ of Thematic Studies - Environmental Change, Linköping University, Linköping, Sweden

*Correspondence: Chuan Tong

Phone: 086-0591-87445659

Email: tongch@fjnu.edu.cn

Fax: 086-0591-83465397

*Correspondence: Derrick Y.F. Lai

Phone: $852-39436528$

Email: dyflai@cuhk.edu.hk

Fax: 852-26035006 


\section{A B S T R A C T}

Wetlands can potentially affect global climate change through their role in modulating the atmospheric concentrations of methane $\left(\mathrm{CH}_{4}\right)$. Their overall $\mathrm{CH}_{4}$ emissions, however, remain the greatest uncertainty in the global $\mathrm{CH}_{4}$ budget. One reason for this is the paucity of long-term field measurements to characterize the variability of $\mathrm{CH}_{4}$ emissions from different types of wetlands. In this study, we quantified $\mathrm{CH}_{4}$ emissions from a brackish, oligohaline Cyperus malaccensis marsh ecosystem in the Min River Estuary in southeast China over five years. Our results showed substantial temporal variability of $\mathrm{CH}_{4}$ emissions from this brackish marsh, with hourly fluxes ranging from $0.7 \pm 0.6$ to $5.1 \pm 3.7 \mathrm{mg} \mathrm{m}^{-2} \mathrm{~h}^{-1}$ (mean $\pm 1 \mathrm{SD}$ ) during the study period. The inter-annual variability of $\mathrm{CH}_{4}$ emissions was significantly correlated with changes in soil temperature, precipitation and salinity, which highlighted the importance of long-term observations in understanding wetland $\mathrm{CH}_{4}$ dynamics. Distinct seasonal patterns in soil $\mathrm{CH}_{4}$ production rates and porewater $\mathrm{CH}_{4}$ concentrations also were observed, and were both positively correlated with $\mathrm{CH}_{4}$ emissions. The seasonal variations of $\mathrm{CH}_{4}$ emissions and production were highly correlated with salinity and porewater sulfate levels. The mean annual $\mathrm{CH}_{4}$ efflux from our site over the five-year period was $23.8 \pm 18.1 \mathrm{~g} \mathrm{CH}_{4} \mathrm{~m}^{-2} \mathrm{yr}^{-1}$, indicating that subtropical brackish tidal marsh ecosystems could release a large amount of $\mathrm{CH}_{4}$ into the atmosphere. Our findings further highlight the need to obtain high-frequency and continuous field measurements over the long term at multiple spatial scales to improve our current estimates of wetland $\mathrm{CH}_{4}$ emissions. Keywords: Methane; Net emissions; Soil production; Porewater; Temporal variation; Estuarine marsh 


\section{Introduction}

The increasing worldwide concern over global climate change and its effects on environmental and human well-beings calls for a better understanding of the magnitude of global greenhouse gas emissions (Tong et al., 2010). Methane $\left(\mathrm{CH}_{4}\right)$ is a potent greenhouse gas with a global warming potential 34 times higher than that of $\mathrm{CO}_{2}$ per mass unit over a 100 -year time scale, and contributes to approximately $20 \%$ of the global radiative forcing (IPCC, 2013). Global atmospheric $\mathrm{CH}_{4}$ levels have increased by threefold since 1750 , reaching $1845 \pm 2$ ppb in 2015 (World Meteorological Organization, 2016). Quantifying the potential source strength of various ecosystems has become one of the top priorities for improving the future predictions of $\mathrm{CH}_{4}$ emissions.

Wetlands are estimated to contribute $20-39 \%$ of the global $\mathrm{CH}_{4}$ emissions (Laanbroek, 2010), with natural wetlands being the single largest source of $\mathrm{CH}_{4}$. Over the past few decades, considerable efforts were made to quantify $\mathrm{CH}_{4}$ emissions from different natural wetlands around the world (e.g. Bubier et al., 1994; Kutzbach et al., 2004; Hendriks et al., 2010; Tong et al., 2012). However, the majority of these field campaigns were carried out over a relatively short period of not more than two years, which provided little knowledge of the inter-annual variability of $\mathrm{CH}_{4}$ emissions from most types of wetlands other than a few exceptions in northern wetlands, e.g. Song et al. (2009), Jackowicz-Korczyński et al. (2010), and Moore et al. (2011). Long-term observations over multiple seasons and years are critical for determining accurate ecosystem $\mathrm{CH}_{4}$ budgets (Song et al., 2009). In addition, the availability of long-term data set will improve ecosystem modelling by providing inputs for model calibration and validation, as well as insights on the key factors regulating wetland $\mathrm{CH}_{4}$ emissions into the atmosphere (Tian et al., 2008; Song 
et al., 2009).

Coastal wetlands, located at the interface between the terrestrial and marine environments, are biogeochemically important ecosystems that span widely from the arctic to the tropical zones (Chmura et al., 2003; Wang et al., 2016). Previous studies have shown that the sediments in coastal wetlands are generally small atmospheric sources (Bartlett \& Harriss, 1993; Poffenbarger et al., 2011; Livesley \& Andrusiak, 2012; Koebsch et al., 2013), or even weak sinks of $\mathrm{CH}_{4}$ (Sun et al., 2013). The low $\mathrm{CH}_{4}$ source strength of coastal wetlands is mainly because of the relatively high sulfate concentrations in marine waters, which favour the activities of sulfate-reducing bacteria while at the same time hamper the metabolism of methanogens through intense competition for substrates (Poffenbarger et al., 2011; Callaway et al., 2012; Vizza et al., 2017). However, some short-term field studies provide evidence that large $\mathrm{CH}_{4}$ emissions from wetlands can occur even when sulfate reduction is a dominant process (Lee et al., 2008; Marín-Muñiz et al., 2015; Holm Jr. et al., 2016). The high uncertainty associated with the magnitude and control of $\mathrm{CH}_{4}$ emissions from coastal wetlands could partly be related to the inherently dynamic environment which introduces a large temporal variability of $\mathrm{CH}_{4}$ fluxes that is not adequately accounted for by s infrequent field measurements.

In this study, monthly $\mathrm{CH}_{4}$ flux measurements were made in a subtropical tidal Cyperus malaccensis (shichito matgrass) marsh in the Min River Estuary in southeast China over five years between 2007-2009, and 2013-2014. We hypothesized that there would be significant seasonal and inter-annual variability in $\mathrm{CH}_{4}$ emissions, which implies that flux estimates would be sensitive to the sampling frequency and study duration. We also investigated the temporal correlations between several environmental variables and soil $\mathrm{CH}_{4}$ production rate, porewater 
$\mathrm{CH}_{4}$ concentration, and net $\mathrm{CH}_{4}$ emissions.

\section{Materials and methods}

\subsection{Site description}

This study was carried out in the Shanyutan wetland $\left(26^{\circ} 00^{\prime} 36^{\prime \prime}-26^{\circ} 03^{\prime} 42^{\prime \prime} \mathrm{N}\right.$, $119^{\circ} 34^{\prime} 12^{\prime \prime}-119^{\circ} 40^{\prime} 40^{\prime \prime}$ E), the largest tidal wetland area (ca. 3120 ha) in the Min River Estuary, southeast China (Fig. 1). The Shanyutan wetland is influenced by a subtropical monsoonal climate, with a mean annual temperature of $19.6{ }^{\circ} \mathrm{C}$ and an annual precipitation of $1350 \mathrm{~mm}$ (Tong et al., 2010). The dominant vegetation species in the Shanyutan wetland included the native Cyperus malaccensis and Phragmites australis, as well as the invasive Spartina alterniflora (smooth cordgrass). The average height of $C$. malaccensis at the site was about $1.4 \mathrm{~m}$. The study site was characterized by semi-diurnal tides, such that the soil surface was submerged for approximately $7 \mathrm{~h}$ over a $24 \mathrm{~h}$ cycle, and at other times, the soil surface was exposed to air (Tong et al., 2010). The average salinity of the tidal water was $4.2 \pm 2.5 \%$ o (Tong et al., 2010).

\subsection{Gas sampling and $\mathrm{CH}_{4}$ flux estimation}

Net $\mathrm{CH}_{4}$ emissions were measured in the intertidal zone in the mid-western part of the Shanyutan wetland $\left(26^{\circ} 01^{\prime} 46^{\prime \prime} \mathrm{N}, 119^{\circ} 37^{\prime} 31^{\prime \prime} \mathrm{E}\right)$, which was dominated by $C$. malaccensis, a widespread plant species at the site. Triplicate $1 \mathrm{~m} \times 1 \mathrm{~m}$ plots, with a distance of $<5 \mathrm{~m}$ between plots, were established for regular measurement of $\mathrm{CH}_{4}$ emissions in the C. malaccensis stand. $\mathrm{CH}_{4}$ flux measurements were carried out monthly from early January to early December in 2007-2009 and 2013-2014. A wooden boardwalk was built to facilitate access to the study plots and minimize potential plot disturbance caused by field measurements. The wooden boardwalk and the study plots were damaged during a major typhoon event in 2010 , thus we built a new 
boardwalk and established new plots adjacent to the damaged ones ( $<15 \mathrm{~m}$ apart) in 2012 . During 2013-2014, we continued with gas flux measurements at the new plots.

$\mathrm{CH}_{4}$ flux measurements were made using static closed chambers and gas chromatography techniques (Hirota et al., 2004; Song et al., 2009; Moore et al., 2011; Marín-Muñiz et al., 2015) with gas samples collected during the neap tides in the morning. The static chamber consisted of two parts: a $30 \mathrm{~cm}$ tall stainless steel bottom collar (length and width of $50 \times 50 \mathrm{~cm}$ in $2007-2009$, and $35 \times 35 \mathrm{~cm}$ in 2013-2014) and a polyvinyl chloride top chamber (length, width and height of $50 \times 50 \times 170 \mathrm{~cm}$ in $2007-2009$, and $35 \times 35 \times 140 \mathrm{~cm}$ in 2013-2014). The bottom collar was inserted into the marsh soils, leaving only $2 \mathrm{~cm}$ above the soil surface, approximately 10 days prior to the first flux measurement, and was then left in place for the duration of the study. A fan was installed inside the chamber to mix the headspace air during gas sampling. During each flux measurement, headspace air samples were drawn into air sampling bags (Dalian Delin Gas Packing Co., Ltd., China) at 10-minute intervals over a total duration of $30 \mathrm{~min}$ in each sampling plot. The total number of gas samples collected per year was $144(12$ months $\times 4$ time intervals $\times$ 3 sites). $\mathrm{CH}_{4}$ concentrations in the gas samples were determined using a gas chromatograph (GC-2010, Shimadzu, Kyoto, Japan) equipped with a flame ionization detector (FID). The rate of $\mathrm{CH}_{4}$ emission $\left(\mathrm{mg} \mathrm{m}^{-2} \mathrm{~h}^{-1}\right.$ ) was calculated based on the slope of the linear regression between $\mathrm{CH}_{4}$ concentration in the chamber headspace and time. The annual (cumulative) $\mathrm{CH}_{4}$ emissions $\left(A E, \mathrm{~g} \mathrm{CH}_{4} \mathrm{~m}^{-2}\right.$ ) (Song et al., 2009; Moore et al., 2011; Xiang et al., 2015) were calculated using Eq. (1):

$$
A E=\sum M F_{i} \times D_{i} \times 24
$$

where $M F_{i}$ is the $\mathrm{CH}_{4}$ flux at the $i$ th month of the year $\left(\mathrm{mg} \mathrm{CH}_{4} \mathrm{~m}^{-2} \mathrm{~h}^{-1}\right)$, and $D_{i}$ is the number of 
days in the $i$ th month of the year.

\subsection{Measurement of soil $\mathrm{CH}_{4}$ production rate}

Soil $\mathrm{CH}_{4}$ production in coastal wetlands has distinct spatio-temporal heterogeneity that could be related to variations in thermal conditions and other abiotic factors (e.g. soil moisture, soil substrate, etc.) (Segers, 1998; Vizza et al., 2017). To assess the variability of soil $\mathrm{CH}_{4}$ production rates across different depths in our marsh, triplicate sediment cores were randomly collected down to a depth of $100 \mathrm{~cm}$ in January (winter), March (spring), July (summer), and October (autumn) of 2012. Intact soil cores were collected using a steel sediment sampler (i.d. $=$ $5 \mathrm{~cm}$ ), sub-divided into ten sections at $10 \mathrm{~cm}$ intervals in the field, and then kept on ice in coolers and transported to the laboratory within $6 \mathrm{~h}$. The rate of soil $\mathrm{CH}_{4}$ production was measured following the method of Wachinger et al. (2000). The chambers $(5 \mathrm{~cm}$ inner diameter, $12 \mathrm{~cm}$ height) used for the anoxic incubation of soil cores were made of polyoxymethylene, which was gas-impermeable and inert to $\mathrm{CH}_{4}$. Before the start of incubation, the chambers were flushed with $\mathrm{N}_{2}$ gas for 15 min to create an anaerobic condition (Wassmann et al., 1998). The cores were then incubated at in situ temperatures, i.e. $10.2,17.5,27.5$, and $21.5{ }^{\circ} \mathrm{C}$ for winter, spring, summer, and autumn, respectively, for a duration of 15 days. We collected $5 \mathrm{~mL}$ gas samples from the chamber using a syringe at three day intervals $(n=5)$ over the course of the incubation, with $\mathrm{N}_{2}$ gas being added after each gas sampling to re-establish the ambient atmospheric pressure. The $\mathrm{CH}_{4}$ concentrations in gas samples were analysed immediately by gas chromatograph. $\mathrm{The} \mathrm{CH}_{4}$ production rates $\left(\mu \mathrm{g} \mathrm{CH}_{4} \mathrm{~g}^{-1}\right.$ (dry weight) day ${ }^{-1}$ ) were calculated based on the rate of change in chamber headspace $\mathrm{CH}_{4}$ concentrations over a 3-day period (Wassmann et al., 1998). The total number of incubations made over the study period was 120 ( 3 replicates $\times 4$ seasons $\times 10$ 
depths).

\subsection{Porewater collection and analysis of dissolved $\mathrm{CH}_{4}$ and $\mathrm{SO}_{4}{ }^{2-}$ concentrations}

Porewater was sampled using the method of in situ dialysis (Ding et al., 2003; Ding et al., 2004a). A series of porewater tubes (5 cm inner diameter) (Ding et al., 2003), with sampling depths of $0-5,5-10,10-15,15-20$ and $20-25 \mathrm{~cm}$, were permanently installed adjacent to each $\mathrm{CH}_{4}$ flux measurement plot, leaving a 5-cm protrusion above the soil surface. The top of each tube was sealed tightly with a cover. Porewater samples were collected in triplicate at each depth interval in January (winter), March (spring), July (summer), and October (autumn) of 2012 and 2013. During each sampling campaign, approximately $10 \mathrm{~mL}$ of soil porewater was extracted using a syringe and discarded. Another $10 \mathrm{~mL}$ of porewater was then collected and transferred into a $20 \mathrm{~mL}$ pre-evacuated vial that was filled with $10 \mathrm{~mL}$ of pure $\mathrm{N}_{2}$ gas (Xiang et al., 2015). About $0.2 \mathrm{~mL}$ of $\mathrm{HgCl}_{2}$ solution was further injected into the porewater samples to inhibit bacterial activities without affecting the solubility of $\mathrm{CH}_{4}$ in water (Butler and Elkins, 1991). The porewater samples were stored at about $4{ }^{\circ} \mathrm{C}$ in a cooler and transported immediately to the laboratory within $24 \mathrm{~h}$ for analysis. The sample vials were shaken vigorously for $10 \mathrm{~min}$ to establish an equilibrium in $\mathrm{CH}_{4}$ concentrations between the dissolved phase in porewater and the gaseous phase in headspace. The headspace $\mathrm{CH}_{4}$ concentrations were determined by gas chromatograph, and the dissolved $\mathrm{CH}_{4}$ concentrations $\left(\mu \mathrm{mol} \mathrm{CH}_{4} \mathrm{~L}^{-1}\right)$ in porewater were then calculated following the methods of Johnson et al. (1990) and Zhang et al. (2010).

To determine porewater $\mathrm{SO}_{4}{ }^{2-}$ concentrations across different soil depths, another triplicate soil cores were collected down to a depth of $100 \mathrm{~cm}$ were collected in January (winter), March (spring), July (summer) and October (autumn) of 2012. The cores were split into ten sub-samples 
at $10 \mathrm{~cm}$ intervals, which were then immediately sealed in a valve bag, kept on ice in coolers, and transported to the laboratory within $6 \mathrm{~h}$. Upon return to the laboratory, porewater was extracted from the soils at each depth interval by centrifugation at $5000 \mathrm{rpm}$ for $10 \mathrm{~min}$ (Cence ${ }^{\circledR}$ L550). The porewater samples were filtered with $0.45 \mu \mathrm{m}$ acetate fibre membranes, and the $\mathrm{SO}_{4}{ }^{2-}$ concentrations were determined using the barium chromate colorimetric method. The soil $\mathrm{SO}_{4}{ }^{2-}$ concentration data for the 90 and $100 \mathrm{~cm}$ depths during the winter were lost due to damage to the incubation chambers.

\subsection{Measurement of environmental variables}

During each sampling campaign, temperature $\left({ }^{\circ} \mathrm{C}\right), \mathrm{pH}$, and electrical conductivity $(\mathrm{EC} ; \mathrm{mS}$ $\mathrm{cm}^{-1}$ ) in the top $15 \mathrm{~cm}$ soils were measured at each site. Soil temperature and $\mathrm{pH}$ were determined in situ by using a handheld $\mathrm{pH} / \mathrm{mV} /$ temperature meter (IQ150, IQ Scientific Instruments, Carlsbad, CA, USA), and soil EC was measured with a EC Meter (2265FS, Spectrum Technologies Inc., Phoenix, AZ, USA). Air temperature $\left({ }^{\circ} \mathrm{C}\right)$ and rainfall were recorded by an automatic meteorological station (LSI-LASTEM, Italy) installed at the Min River Estuary Station of the China Wetland Ecosystem Research Network.

\subsection{Data analysis and model formation}

Data were log-transformed to approximate normal distributions when selected attributes were skewed. The coefficients of variation $(\mathrm{CV})$ for $\mathrm{CH}_{4}$ fluxes and environmental variables were calculated by dividing the standard deviation by the mean to determine the magnitude of interannual (among the 5 years) and interseasonal variability (among the 20 seasons observed) (Musavi et al., 2017). Two-way analysis of variance (ANOVA) was used to explore whether seasonality, soil depths or their interaction have fixed effects on soil $\mathrm{CH}_{4}$ production rates or 
porewater $\mathrm{CH}_{4}$ concentrations, with soil sulfate $\left(\mathrm{SO}_{4}{ }^{2-}\right)$ concentration being a covariate.

We recognised that the above formed statistical models in this study might not fit the assumptions of ANOVA, rendering the formal inference based on the p-value of ANOVA potentially unreliable. Apart from the ANOVA models, different mixed-effect models were also used to investigate how soil depths were related to soil $\mathrm{CH}_{4}$ production rates or porewater $\mathrm{CH}_{4}$ concentrations, because it would be more feasible to model the variance structure of soil depths in the mixed-effect model framework than ANOVA. Since the different models for soil depths were not nested, likelihood ratio tests could not be used, and the Akaike information criterion (AIC) was used instead for model comparison.

To take into account the possible spatial autocorrelations of soil $\mathrm{CH}_{4}$ production rates or porewater $\mathrm{CH}_{4}$ concentrations down the soil profile, we also considered soil depth as a random effect variable in the linear mixed-effect model using the lme function in the nlme package of $\mathrm{R}$ (Pinheiro et al., 2017). Our results showed that the AIC values of models fitting soil depth as a fixed factor for both soil $\mathrm{CH}_{4}$ production rates and porewater $\mathrm{CH}_{4}$ concentrations (158 and 55, respectively) were significantly lower than those fitting soil depth as a random effect variable (211 and 90, respectively). Hence, we only presented results obtained from the former models fitting soil depth as a fixed factor, which performed slightly better than the mixed linear model.

Linear mixed-effect models were also used to test for differences in interseasonal variability of $\mathrm{CH}_{4}$ fluxes within sites after accounting for the possible effects of air temperature, soil temperature, precipitation, soil $\mathrm{pH}$ and water salinity, with sampling year being fitted as a random intercept to account for the repeated measures of other factors, i.e. interseasonal variability $\sim$ air temperature + soil temperature + precipitation + soil $\mathrm{pH}+$ salinity, random $=\sim 1 \mid$ Year. Similarly, 
linear mixed-effect models were used to test for the possible predictors of the variations in $\mathrm{CH}_{4}$ flux, with the sampling site being selected as a random effect variable to account for the repeated measures in spatial $\mathrm{CH}_{4}$ flux i.e., $\mathrm{CH}_{4}$ flux $\sim$ air temperature + soil temperature + precipitation + soil $\mathrm{pH}+$ salinity, random $=\sim 1 \mid$ site. In order to test for temporal autocorrelation, we plotted autocorrelation function (ACF) and partial autocorrelation (PACF) plots of the residuals to help interpretation of the $\mathrm{CH}_{4}$ flux data. Following Bader et al. (2013), we refitted a model including an autocorrelation function with a first-order autoregressive correlation structure (AR1), specified as "correlation $=$ corAR1 (form $=\sim$ date $\mid$ site)", to account for the repeated measures on 60 different days at the three sites to model the violation of independence of residuals from different sampling days. Significant difference between models with and without AR1 was tested by the anova function in $\mathrm{R}$, and the model with AR1 that showed a significantly lower AIC value was chosen. A variable selection with the fitted global models based on the AIC algorithm and a relative importance method were then used to quantify the contributions of the best predictors (the significant variables of the final model) of the variations in $\mathrm{CH}_{4}$ flux and their interseasonal variability. For the model selection, we used the stepAIC() function in the R package "MASS", accompanied by the calc.relimp() function with Lindeman-Merenda-Gold (LMG) relative importance method in the R package "relaimpo" (Musavi et al., 2017). The model with the lowest AIC value was chosen, and the relationship between the dependent variables and chosen predictors was further tested by Type II Wald's test implemented in the R package “car”.

Besides, the differences in the mean values of environmental variables (precipitation, temperature, soil $\mathrm{pH}$, and soil EC) over the five years were also examined by repeated measures analysis of variance (RMANOVA). For the dataset of each individual year, Pearson correlation 
analysis was used to examine the relationships (1) between environmental variables and $\mathrm{CH}_{4}$ emissions, soil $\mathrm{CH}_{4}$ production rates, or porewater $\mathrm{CH}_{4}$ concentrations, and (2) between $\mathrm{CH}_{4}$ emissions and soil $\mathrm{CH}_{4}$ production rates or porewater $\mathrm{CH}_{4}$ concentrations. The interseasonal variability (ISV) of salinity and $\mathrm{CH}_{4}$ fluxes was determined by dividing the standard deviation of the variables measured at triplicate sampling sites by the average value obtained in each individual season. Temperature sensitivity ( $Q_{10}$ value) of $\mathrm{CH}_{4}$ emissions was calculated following the exponential regression model described by Tong et al. (2015) and Wang et al. (2015). All statistical analyses were performed using R version 3.4.1 (R Development Core Team 2017) and a $P$ value of $<0.05$ was considered statistically significant for multiple comparisons. All data were reported as mean \pm 1 standard error $(\mathrm{SE})$. All statistical graphs were generated using OriginPro 7.5 (OriginLab Corp. USA).

\section{Results}

\subsection{Temporal variations in environmental variables}

Figure 2 shows the temporal variations in soil temperature, $\mathrm{pH}$, and EC, all of which showed similar patterns over time for the majority of the study periods. Considerably higher air and soil temperatures and lower EC were observed between May and September than in other months (Fig. 2). Soil pH showed no clear seasonal patterns but varied slightly among measurement events. Over the five-year period, the mean annual air temperatures were very close to the historical average of $22.2{ }^{\circ} \mathrm{C}$ (Table 1) while the monthly mean air temperatures followed the long-term historical patterns, with July and August usually being the warmest months and January and February the coldest (Fig. 2). Fig. S1 shows the monthly precipitation amounts over the five study years, which varied significantly both seasonally and inter-annually. Nearly half of 
the annual rainfall occurred in summer, with several heavy rainfall events in July and August. Significantly higher annual precipitation was observed in 2013, while lower precipitation occurred in 2007 and 2009.

\subsection{Dynamics of soil $\mathrm{CH}_{4}$ production rates and porewater $\mathrm{CH}_{4}$ concentrations}

The range of average soil $\mathrm{CH}_{4}$ production rates across all depths among the four seasons was large, spanning three orders of magnitude from 0.04 to $1.67 \mu \mathrm{g} \mathrm{CH}_{4} \mathrm{~g}^{-1}$ day $^{-1}$. Soil $\mathrm{CH}_{4}$ production rates varied significantly with season and soil depth $(P<0.05)$ (Table 2 and Fig. 3). The highest and lowest soil $\mathrm{CH}_{4}$ production rates were observed in the summer and winter, respectively (Table 2 and Fig. 3). Significantly higher $\mathrm{CH}_{4}$ prolduction rates were observed from the topsoil $(5-15 \mathrm{~cm})$ as compared to other soil depths during the spring, summer, and autumn $(P$ $<0.05$ ) (Table 2 and Fig. 3), indicating a decreasing trend with depth. There were also significant interactions between seasons and soil depths in affecting soil $\mathrm{CH}_{4}$ production rates $(P<0.05)$ (Table 2).

Fig. 4 shows the seasonal variations in dissolved $\mathrm{CH}_{4}$ concentrations down the soil profile. Porewater $\mathrm{CH}_{4}$ concentrations varied significantly with both depth and season $(P<0.01)$ (Table 2), ranging between 2 and $457 \mu \mathrm{mol} \mathrm{L}{ }^{-1}$ (Fig. 3). We observed a significant, increasing trend of porewater $\mathrm{CH}_{4}$ concentrations with depths (Table 2 and Fig. 4), and substantially higher $\mathrm{CH}_{4}$ concentrations at all depths during the summer $(P<0.01)$ (Table 2 and Fig. 4).

\subsection{Temporal variations in $\mathrm{CH}_{4}$ emissions}

\subsubsection{Seasonal variations in $\mathrm{CH}_{4}$ emissions}

Across all years, the highest $\mathrm{CH}_{4}$ emissions were observed between April and October (Fig. 5). Fluxes were generally low between November and March, except in 2013 in which the peak 
of $\mathrm{CH}_{4}$ emission occurred in December and January. When averaging the monthly fluxes over five years, a strong seasonal pattern in $\mathrm{CH}_{4}$ emissions emerged, with generally low values in spring, a maximum in summer, and a minimum in winter (Fig. 6). Meanwhile, we observed considerable variations in both mean $\mathrm{CH}_{4}$ fluxes (Table 1) and the timing of maximum emissions (Fig. 5) among different years. For example, the maximum $\mathrm{CH}_{4}$ emissions occurred in May-June in 2013, but in August-October in 2014. Clear peaks of $\mathrm{CH}_{4}$ emissions were not observed in 2007 and 2009, with only slightly higher fluxes being detected between April and October. Salinity showed clear links to the seasonal variability of $\mathrm{CH}_{4}$ emissions (Table 3), with a significant negative correlation observed between the two (Table 4). When considering the variability in the $\mathrm{CH} 4$ emission ( $\mathrm{SD}$ divided by mean or $\mathrm{CV}$ ), is was positively correlated with the equivalent variability in salinity (Fig. 7); i.e. emissions varied more when also salinity was variable among measurements.

\subsubsection{Inter-annual variations in $\mathrm{CH}_{4}$ emissions}

The coefficient of variation of annual mean $\mathrm{CH}_{4}$ emissions over the five years was $67 \%$, which implied a considerable inter-annual variability. Over the study period, the mean annual $\mathrm{CH}_{4}$ emissions from the C. malaccensis marsh ranged between 0.71 and $5.10 \mathrm{mg} \mathrm{CH}_{4} \mathrm{~m}^{-2} \mathrm{~h}^{-1}$, leading to annual cumulative emissions of 6.2-48.9 $\mathrm{g} \mathrm{CH}_{4} \mathrm{~m}^{-2}$ (Fig. 5 and Table 1). Significantly lower and higher $\mathrm{CH}_{4}$ effluxes were observed in 2007 and 2013, respectively, as compared to other years (Table 1). According to the AIC-based model selection, variations in $\mathrm{CH}_{4}$ emissions were best predicted by soil temperature, precipitation and salinity (represented by EC) (Table 3), which independently explained $60.0 \%$ (positive effect), $21.7 \%$ (positive effect) and $18.2 \%$ (negative effect) of the variations, respectively (Fig. 7). 


\section{Discussion}

\subsection{Variability of soil $\mathrm{CH}_{4}$ production rates and porewater $\mathrm{CH}_{4}$ concentrations}

Soil $\mathrm{CH}_{4}$ production rates from our estuarine marsh demonstrated significant variations down the soil profile (Table 2 and Fig. 3), with the highest rates occurring in the top soil layer (5-15 cm depth) in all seasons except winter, which was in accordance with the results of previous studies (van den Pol-van Dasselaar \& Oenema, 1999; Liu et al., 2011; Knoblauch et al., 2015). We found a negative correlation between soil $\mathrm{CH}_{4}$ production rates and porewater $\mathrm{SO}_{4}{ }^{2-}$ concentrations along the soil profile (Fig. S2). The higher porewater $\mathrm{SO}_{4}{ }^{2-}$ concentrations in the deeper soil layer can help the sulfate-reducing bacteria in outcompeting the methanogens for substrates, thereby inhibiting $\mathrm{CH}_{4}$ production at depth (van der Gon et al., 2001; Purdy et al., 2003; Vizza et al., 2017). The vertical distribution of $\mathrm{CH}_{4}$ production rates down the soil profile might also be related to the differences in substrate quantity and quality. Previous studies in wetlands have shown that soil $\mathrm{CH}_{4}$ production rate increased with the availability of labile carbon fractions (Updegraff et al., 1995; Liu et al., 2011; Inglett et al., 2012). A previous study conducted at our site has shown that the majority of $C$. malaccensis root biomass was distributed in the upper surface layer (Tong et al., 2011), which could provide an abundant supply of labile carbon to support the metabolic activity of methanogens (Ström et al., 2012). On the other hand, we found a significant increase in porewater $\mathrm{CH}_{4}$ concentrations with depth, which was opposite to the pattern of $\mathrm{CH}_{4}$ production rates in the soil profile (Table 2 and Fig. 4). The concentration of $\mathrm{CH}_{4}$ in porewater is influenced by both $\mathrm{CH}_{4}$ production and loss. In spite of a high $\mathrm{CH}_{4}$ production rate in the top soils, we hypothesize that the lower porewater $\mathrm{CH}_{4}$ concentration observed could be related to the tidal actions, which are one of the key physical processes 
shaping the biogeochemical processes in coastal wetlands (Tong et al., 2010). The top soil layers were subjected to frequent tidal flushing, which could enhance $\mathrm{CH}_{4}$ export to the tidal waters and reduce the accumulation of $\mathrm{CH}_{4}$ in porewater (Lee et al., 2008). In addition, the inflow of tidal water would bring along a large amount of oxygen and $\mathrm{SO}_{4}{ }^{2-}$ to the surface soils, thereby increasing the soil redox potential and promoting methanotrophy in the upper layers (Ding et al., 2003; Sun et al., 2013).

We observed distinct seasonal variations in soil $\mathrm{CH}_{4}$ production rates with significantly higher values in the summer (Table 2 and Fig. 3), which were in accordance with the findings of previous studies (Bergman et al., 2000; Avery et al., 2003; Tong et al., 2012). Similarly, porewater $\mathrm{CH}_{4}$ concentrations were found to be significantly higher during the summer season. It is generally acknowledged that $\mathrm{CH}_{4}$ production rates would vary seasonally as a function of temperature (e.g. Segers, 1998; Inglett et al., 2011). In our study, soil temperature had an exponential relationship with soil $\mathrm{CH}_{4}$ production rates (Fig. S3), and positive correlation with porewater $\mathrm{CH}_{4}$ concentrations ( $\left.r=0.662, p<0.01, n=24\right)$, pointing to the positive impacts of temperature on microbial-mediated methanogenesis. Moreover, the amount of plant biomass in this wetland was found to be much higher in summer than in winter (Tong et al., 2011). The enhanced plant productivity and subsequently supply of labile carbon substrates through root exudation in the summer period would likely play a role in stimulating methanogenic activities (Whiting \& Chanton, 1993; Bergman et al., 2000; Walter et al., 2001) and hence increasing the concentrations of $\mathrm{CH}_{4}$ in soil porewater (Xiang et al., 2015). In addition, the increased freshwater discharge from the estuary in summer time provided a dilution effect that significantly reduced the salinity of tidal water, which would in part facilitate methanogenesis through reduced 
competition with sulfate-reducing bacteria (Sinke et al., 1992). We observed a significant and negative correlation between salinity and porewater $\mathrm{CH}_{4}$ concentration $(r=-0.653, p<0.01, n=$ 24) that supported this hypothesis.

\subsection{Temporal variations of $\mathrm{CH}_{4}$ emissions}

\subsubsection{Seasonal variability}

In this study, $\mathrm{CH}_{4}$ emissions from the subtropical estuarine marsh varied considerably among different seasons. The seasonal mean $\mathrm{CH}_{4}$ emissions over the five-year period were correlated significantly with both soil $\mathrm{CH}_{4}$ production rates $(0-20 \mathrm{~cm}$ depth) (Fig. S4) and porewater $\mathrm{CH}_{4}$ concentrations (Fig. S5). As such, the seasonal pattern of $\mathrm{CH}_{4}$ emission (Fig. 6) was highly similar to that of soil $\mathrm{CH}_{4}$ production rates (Fig. 3) and porewater $\mathrm{CH}_{4}$ concentrations (Fig. 4). This strong relationship was expected since a high $\mathrm{CH}_{4}$ production rate in soils would increase the supply of $\mathrm{CH}_{4}$ to soil porewater, and subsequently enhance net $\mathrm{CH}_{4}$ emissions to the atmosphere owing to the steeper concentration gradient.

The seasonal variability of $\mathrm{CH}_{4}$ emissions could be governed by the interactions of a number of environmental variables. Our results showed that salinity was clearly and negatively correlated with the variations of $\mathrm{CH}_{4}$ flux among different seasons (Table 3 and Table 4). Numerous studies have reported a significant reduction in $\mathrm{CH}_{4}$ emissions from coastal wetlands with salinity (Bartlett et al., 1987; Magenheimer et al., 1996; Poffenbarger et al., 2011; Tong et al., 2012; Sun et al., 2013; Vizza et al., 2017). The significantly lower soil salinity (represented by EC) observed between May and September in our site could significantly enhance methanogenic activities owing to reduced presence of alternate electron acceptors (Welti et al., 2017). Salinity could also affect $\mathrm{CH}_{4}$ production through its effects on extracellular enzyme activities and carbon 
mineralization rates (Chambers et al., 2013; Neubauer et al., 2013). Meanwhile, salinity might also affect methanotrophic activities directly or indirectly, which in turn alter the rate of $\mathrm{CH}_{4}$ emissions from wetlands. Only few studies have thus far directly examined the mechanistic processes, i.e. $\mathrm{CH}_{4}$ production and oxidation, involved in the suppression of net $\mathrm{CH}_{4}$ flux by salinity (Vizza et al., 2017). Further studies should be carried out to explore the exact impacts of salinity on various biogeochemical processes in soils in affecting $\mathrm{CH}_{4}$ dynamics.

Temperature was another important predictor of the changes in $\mathrm{CH}_{4}$ emissions from our $C$. malaccensis marsh, as shown by the strong relationships observed between air/soil temperature and $\mathrm{CH}_{4}$ flux in individual years (Table 4). An increase in temperature could enhance $\mathrm{CH}_{4}$ emissions by increasing methanogenic activities, stimulating root exudations (Song et al., 2009; Yvon-Durocher et al., 2014; Olsson et al., 2015), as well as facilitating plant-mediated $\mathrm{CH}_{4}$ transport (Hosono and Nouchi, 1997). Meanwhile, we found that the temperature sensitivity of $\mathrm{CH}_{4}$ flux varied considerably among different years over the study period, with $Q_{\text {air10 }}$ and $Q_{\text {soil10 }}$ values ranging from 2.46 to 5.30 , and from 3.66 to 7.92 , respectively (Fig. S6). Our results suggest that the estimation of long-term (multi-year) $\mathrm{CH}_{4}$ emissions based on simple extrapolations of the relationships between temperature and $\mathrm{CH}_{4}$ flux derived from short-term $(<$ 1 year) measurements might not be reliable and introduce significant biases. Apart from temperature, the hydrologic conditions of the site could also affect $\mathrm{CH}_{4}$ emissions by controlling the depths of the oxic and anoxic layers as well as soil redox potential (Dinsmore et al., 2009). The disproportionately high amount of precipitation received during the summer (Fig. S1) could favour the formation of a wetter and more anaerobic environment in the soils for methanogenesis (Lai et al., 2014). Furthermore, the total amount of plant biomass (aboveground + belowground) 
at our marsh site was found to vary significantly among seasons in the following order: summer $>$ autumn $>$ spring $>$ winter (Tong et al., 2011), which could exert influences on the variability of plant-mediated $\mathrm{CH}_{4}$ emissions via primary production and substrate supply.

Based on our five-year data set, we observed that peak $\mathrm{CH}_{4}$ emissions generally occurred during the summer period when temperature was high and conductivity was low, which favored methanogenesis. Yet, the exact timing of peak $\mathrm{CH}_{4}$ emissions varied from one year to another that could be partly related to the inter-annual variations in the timing of maximum monthly precipitation, which governed the extent of anaerobic conditions in soils. For instance, the timing of peak $\mathrm{CH}_{4}$ emission coincided with that of maximum monthly precipitation in 2008 and 2014, which happened to be in the months of July and August, respectively. Yet, in 2013, the extremely high precipitation amount in July implied a lack of abundant sunlight during this period, which could hinder photosynthesis by marsh plants and the supply of labile carbon from photosynthates to soils for methanogenesis. Our results point to a need of carrying out more in-depth studies in future to disentangle the specific influences of various environmental factors on the seasonal variability of $\mathrm{CH}_{4}$ emission in coastal marshes.

\subsubsection{Inter-annual variability}

In the present study, $\mathrm{CH}_{4}$ emissions from the brackish Cyperus malaccensis marsh showed substantial inter-annual variability (Fig. 5 and Table 3). Previous studies have shown that the inter-annual variability of $\mathrm{CH}_{4}$ emissions was governed by water table position (Moore et al., 2011), peat temperature (Shannon and White, 1994; Lai et al., 2014), and precipitation (Song et al., 2009). According to the AIC-based model selection, we found that soil temperature and salinity were the primary determinants of the inter-annual variability of $\mathrm{CH}_{4}$ flux at our site 
(Table 3 and Fig. 7a). The effects of soil temperature and salinity could be related to the production of substrate precursors and methanogenic activity as described previously (Whalen et al., 2005; Dinsmore et al., 2009; Lai et al., 2014; Yvon-Durocher et al., 2014). In addition, we found strong correlations between $\mathrm{CH}_{4}$ flux and precipitation amount over the study period (Table 4). Among the five study years, the lowest annual mean precipitation was recorded in 2007 , which was significantly lower than that in 2008, 2013 and 2014 (1362 vs. 1485-1890 mm, $p$ $<0.05$, Fig. S1). It was likely that the much lower $\mathrm{CH}_{4}$ emission observed in 2007 was at least partly related to the significantly lower amount of precipitation received in this particularly dry year, which provided a more aerobic and less favorable environment for methanogenesis to take place. Other factors, such as primary productivity and water table depth, might also contribute to the inter-annual variations in $\mathrm{CH}_{4}$ flux and deserve further investigations.

It is noteworthy that significantly higher $\mathrm{CH}_{4}$ emissions were observed in 2013 and 2014 as compared to other years ( $p<0.05$; Table 1$)$, which could be related to the increased discharge of nutrient-enriched effluents from the aquaculture ponds in the surrounding region. Starting from 2011, the conversion of natural tidal marshes into aquaculture ponds has become increasingly dominant in the Shanyutan wetland. A previous study estimated that about $29 \%$ of total nitrogen and $16 \%$ of total phosphorus added to the ponds in the form of feeds and fertilizers were actually assimilated by fish and shrimps during a production cycle (Avnimelech and Ritvo, 2003). The majority of added nitrogen and phosphorus would then eventually be discharged as effluents that are rich in particulate matters (e.g. uneaten feeds, faeces, phytoplankton) and dissolved nutrients (Jackson et al., 2004; Molnar et al., 2013) into the adjacent waterbodies, further stimulating microbially-mediated $\mathrm{CH}_{4}$ emissions. Studies based on both laboratory incubations and field 
measurements have demonstrated the positive effects of exogenous nutrient loading on $\mathrm{CH}_{4}$ production and emissions (Liu and Greaver, 2009; Chen et al., 2010). Hu et al. (2017) also reported that the addition of nitrogen strongly stimulated $\mathrm{CH}_{4}$ emissions from the $C$. malaccensis marsh in our study area.

\subsection{Implications and further outlook}

It is generally considered that coastal wetlands have a lower $\mathrm{CH}_{4}$ emission rate than other natural wetlands owing to the inhibitory effect of high $\mathrm{SO}_{4}{ }^{2-}$ concentrations (Bartlett et al., 1987; Ding et al., 2004b; Saarnio et al., 2009; Poffenbarger et al., 2011). However, we found that the mean annual $\mathrm{CH}_{4}$ emission from our subtropical brackish marsh in the Min River Estuary was $23.8 \pm 18.1 \mathrm{~g} \mathrm{CH}_{4} \mathrm{~m}^{-2} \mathrm{yr}^{-1}$, which was 1.8 times higher than the average of $13.3 \mathrm{~g} \mathrm{CH}_{4} \mathrm{~m}^{-2} \mathrm{yr}^{-1}$ across China's natural wetlands (Wei and Wang, 2017), and also substantially higher than the annual $\mathrm{CH}_{4}$ flux reported in the Atlantic blanket bogs (5.5-6.2 $\mathrm{g} \mathrm{CH}_{4} \mathrm{~m}^{-2} \mathrm{yr}^{-1}$ ) (Laine et al., 2007; Koehler et al., 2011), Finnish bogs (5.2-6.8 $\mathrm{g} \mathrm{CH}_{4} \mathrm{~m}^{-2} \mathrm{yr}^{-1}$ ) (Alm et al., 1999), as well as Swedish and Minnesota fens (12.0-19.5 $\mathrm{g} \mathrm{CH}_{4} \mathrm{~m}^{-2} \mathrm{yr}^{-1}$ ) (Shurpali et al., 1993; Rinne et al., 2007; Nilsson et al., 2008). The range of $\mathrm{CH}_{4}$ emissions from our brackish marsh $\left(6.19-48.86 \mathrm{~g} \mathrm{CH}_{4} \mathrm{~m}^{-2} \mathrm{yr}^{-1}\right)$ was also comparable to that from the coastal wetlands in South India (17.3-118.4 $\left.\mathrm{g} \mathrm{CH}_{4} \mathrm{~m}^{-2} \mathrm{yr}^{-1}\right)$ (Purvaja and Ramesh, 2001), freshwater marshes in Europe (10-90 $\mathrm{g} \mathrm{CH}_{4} \mathrm{~m}^{-2} \mathrm{yr}^{-1}$ ) (Saarnio et al., 2009), and freshwater marshes in China (4.9-94.1 $\mathrm{g} \mathrm{CH}_{4} \mathrm{~m}^{-2} \mathrm{yr}^{-1}$ ) (Ding et al., 2004b). Our results suggest that subtropical estuarine brackish marshes could be important sources of atmospheric $\mathrm{CH}_{4}$ and thus should not be overlooked in greenhouse gas accounting for their contributions to global climate change.

Numerous efforts have been made to estimate regional $\mathrm{CH}_{4}$ emissions from coastal wetlands 
by extrapolating short-term $(<2$ year) field measurements to longer periods in a given area (e.g. Purvaja and Ramesh, 2001; Ding et al., 2004b; Saarnio et al., 2009; Ortiz-Llorente and Alvarez-Cobelas, 2012). However, our results show that $\mathrm{CH}_{4}$ emissions from the estuarine marshes had strong inter-annual variability, which suggest a high uncertainty of regional estimates of $\mathrm{CH}_{4}$ emissions relying only on short-term measurements. It is of paramount importance to take into account long-term observations in order to reduce the uncertainty of $\mathrm{CH}_{4}$ flux estimations and improve our understanding of the impacts of wetlands on the atmospheric $\mathrm{CH}_{4}$ balance. Moreover, most of the existing process-based models used for estimating $\mathrm{CH}_{4}$ flux from coastal wetlands fail to consider the influence of salinity (Li et al., 2016). In this study, we observed a significant and strong negative relationship between salinity and $\mathrm{CH}_{4}$ emissions (Table 3 and Table 4), indicating that the interactions between temperature, salinity, and other biotic/abiotic factors should be addressed comprehensively to improve the current $\mathrm{CH}_{4}$ flux models.

It should be noted that the findings of this study were limited by several uncertainties, which could be associated with the following aspects: (1) single time-point measurements do not fully capture the episodic and high magnitude events of $\mathrm{CH}_{4}$ release; (2) a limited number of flux measurement sites results in a lack of adequate spatial representation; (3) chamber measurement problems, such as changes in temperature; and (4) the lack of $\mathrm{CH}_{4}$ emission observations during flood tide. Future research programs will thus need to increase the frequency of sampling in situ for longer periods and at different spatial scales as well as include innovative techniques (e.g. eddy covariance tower) in order to measure $\mathrm{CH}_{4}$ releases from coastal marshes.

\section{Conclusions}


Our long-term measurements of $\mathrm{CH}_{4}$ emissions from the subtropical estuarine brackish $C$. malaccensis marsh ecosystem in the Min River Estuary, southeast China over five years revealed strong inter-annual and seasonal variabilities of $\mathrm{CH}_{4}$ fluxes. The temporal variations in $\mathrm{CH}_{4}$ emissions from our marsh were mainly related to the variations in soil temperature and salinity, while the potential roles of primary productivity and precipitation should not be overlooked. Our results suggest that long-term, high-frequency observation of $\mathrm{CH}_{4}$ emissions is essential for making reliable flux estimates from the coastal marshes. In addition, the significant relationships among soil $\mathrm{CH}_{4}$ production rates, porewater $\mathrm{CH}_{4}$ concentrations, and net $\mathrm{CH}_{4}$ emissions observed in this study highlight the great potential in successfully simulating these processes using biogeochemical models once the influences of key environmental factors are properly quantified.

\section{Acknowledgements}

This research was supported financially by the National Science Foundation of China (nos. 41801070, 41877335, and 41671088), the Program for Innovative Research Team at Fujian Normal University (IRTL1205), the Key Sciences and Technology Project of Fujian Province (2014R1034-1), the Study-Abroad Grant Project for Graduates of the School of Geographical Sciences, and the Graduated Student Science and Technology Innovation Project of the School of Geographical Science, Fujian Normal University (GY201601). D. Bastviken was funded by the Swedish Research Council VR, Linköping University, and the European Research Council ERC (grant no. 725546). We thank Prof. Margaret Oliver and Dr. Carmella Vizza for their valuable comments and suggestions. We would like to thank Chuan-yu Gao of the Northeast Institute of Geography and Agroecology, Chinese Academy of Sciences, for his technical support.

\section{References}


Alm, J., Saarnio, S., Nykänen, H., Silvola, J., Martikainen, P., 1999. Winter $\mathrm{CO}_{2}, \mathrm{CH}_{4}$ and $\mathrm{N}_{2} \mathrm{O}$ fluxes on some natural and drained boreal peatlands. Biogeochemistry, 44, 163-186.

Avery, G.B., Shannon, R.D., White, J.R., Martens, C.S., Alperin, M.J., 2003. Controls on methane production in a tidal freshwater estuary and a peatland: methane production via acetate fermentation and $\mathrm{CO}_{2}$ reduction. Biogeochemistry 62, 19-37.

Avnimelech, Y., Ritvo, G., 2003. Shrimp and fish pond soils: processes and management. Aquaculture 220, $549-567$.

Bader, M.K.F., Leuzinger, S., Keel, S.G., Siegwolf, R.T.W., Hagedorn, F., Schleppi, P., Körner, C., 2013. Central European hardwood trees in a high- $\mathrm{CO}_{2}$ future: Synthesis of an 8-year forest canopy $\mathrm{CO}_{2}$ enrichment project. J. Ecol. 101(6), 1509-1519.

Bartlett, K.B., Bartlett, D.S., Harriss, R.C., Sebacher, D.I., 1987. Methane emission along a salt marsh salinity gradient. Biogeochemistry 4, 183-202.

Bartlett, K.B., Harriss, R.C., 1993. Review and assessment of methane emissions from wetlands. Chemosphere $26,261-320$.

Bergman, I., Klarqvist, M., Nilsson, M., 2000. Seasonal variation in rates of methane production from peat of various botanical origins: effects of temperature and substrate quality. FEMS Microbiol. Ecol. 33, $181-189$.

Bubier, J.L., Moore, T.R., 1994. An ecological perspective on methane emissions from northern wetlands. Trends Ecol. Evol. 9, 460-464.

Butler, J.H., Elkins, J.W., 1991. An automated technique for the measurement of dissolved $\mathrm{N}_{2} \mathrm{O}$ in natural waters. Mar. Chem. 34, 47-61.

Callaway, J.C., Borgnis, E.L., Turner, R.E., Milan, C.S., 2012. Carbon sequestration and sediment accretion in San Francisco Bay tidal wetlands. Estuar. Coast. 35, 1163-1181.

Chambers, L.G., Osborne, T.Z., Reddy, K.R., 2013. Effect of salinity-altering pulsing events on soil organic carbon loss along an intertidal wetlands gradient: a laboratory experiment. Biogeochemistry 115, 363-383.

Chen, G.C., Tam, N.F.Y., Ye, Y., 2010. Summer fluxes of atmospheric greenhouse gases $\mathrm{N}_{2} \mathrm{O}, \mathrm{CH}_{4}$ and $\mathrm{CO}_{2}$ from mangrove soil in South China. Sci. Total Environ. 408, 2761-2767.

Chmura, G.L., Anisfeld, S.C., Cahoon, D.R., Lynch, J.C., 2003. Global carbon sequestration in tidal, saline wetland soils. Global Biogeochem. Cy. 17(4), 1111, doi:10.1029/2002GB001917.

Dinsmore, K.J., Skiba, U.M., Billett, M.F., Rees, R.M., 2009. Effect of water table on greenhouse gas emissions from peatland mesocosms. Plant Soil 318, 229-242. 
Ding, W.X., Cai, Z.C., Tsuruta, H., 2004a. Diel variation in methane emissions from the stands of Carex lasiocarpa and Deyeuxia angustifolia in a cool temperate freshwater marsh. Atmos. Environ. 38, 181-188.

Ding, W.X., Cai, Z.C., Wang, D.X., 2004b. Preliminary budget of methane emissions from natural wetlands in China. Atmos. Environ. 38, 751-759.

Ding, W.X., Cai, Z.C., Tsuruta, H., Li, X.P., 2003. Key factors affecting spatial variation of methane emissions from freshwater marshes. Chemosphere 51, 167-173.

Hendriks, D.M.D, van Huissteden, J., Dolman, A.J., 2010. Multi-technique assessment of spatial and temporal variability of methane fluxes in a peat meadow. Agr. Forest Meteorol. 150, 757-774.

Hirota, M., Tang, Y.H, Hu, Q.W, Hirata, S., Kato, T., Mo, W.H, Cao, G.M., Mariko, S., 2004. Methane emissions from different vegetation zones in a Qinghai-Tibetan Plateau wetland. Soil Biol. Biochem. 36, $737-748$.

Holm Jr, G.O., Perez, B.C., McWhorter, D.E., Krauss, K.W., Johnson, D.J., Raynie, R.C., Killebrew, C.J., 2016. Ecosystem level methane fluxes from tidal freshwater and brackish marshes of the Mississippi River Delta: implications for coastal wetland carbon projects. Wetlands 36, 401-413.

Hosono, T., Nouchi, I., 1997. The dependence of methane transport in rice plants on the root zone temperature. Plant Soil 191, 233-240.

Hu, M.J., Wilson, B.J., Sun, Z.G., Ren, P., Tong, C., 2017. Effects of the addition of nitrogen and sulfate on $\mathrm{CH}_{4}$ and $\mathrm{CO}_{2}$ emissions, soil, and pore water chemistry in a high marsh of the Min River estuary in southeastern China. Sci. Total Environ. 579, 292-304.

Inglett, K.S., Inglett, P.W., Reddy, K.R, Osborne, T.Z., 2012. Temperature sensitivity of greenhouse gas production in wetland soils of different vegetation. Biogeochemistry 108, 77-90.

IPCC. 2013 In: Stocker, T.F, Qin, D., Plattner, G.K., Tignor, M., Allen, S.K., Boschung, J., Nauels, A., Xia, Y., Bex, V., Midgley, P.M., (Eds.). Climate Change 2013: the Physical Science Basis. Contribution of Working Group I to the Fifth Assessment Report of the Intergovernmental Panel on Climate Change. Cambridge University Press, Cambridge, United Kingdom and New York, NY, USA.

Jackowicz-Korczyński, M., Christensen, T.R., Bäckstrand, K., Crill, P., Friborg, T., Mastepanov, M., Ström, L., 2010. Annual cycle of methane emission from a subarctic peatland. J. Geophys. Res-Biogeo. 115, G02009, doi:10.1029/2008JG000913.

Jackson, C., Preston, N., Thompson, P., 2004. Intake and discharge nutrient loads at three intensive shrimp farms. Aquac. Res. 35, 1053-1061.

Johnson, K.M., Hughes, J.E., Donaghay, P.L., Sieburth, J.M., 1990. Bottle-calibration static head space method 
for the determination of methane dissolved in seawater. Anal. Chem. 62, 2408-2412.

Knoblauch, C., Spott, O., Evgrafova, S., Kutzbach, L., Pfeiffer, E.M., 2015. Regulation of methane production, oxidation, and emission by vascular plants and bryophytes in ponds of the northeast Siberian polygonal tundra. J. Geophys. Res-Biogeo. 120, 2525-2541.

Koebsch, F., Glatzel, S., Jurasinski, G., 2013. Vegetation controls methane emissions in a coastal brackish fen. Wetl. Ecol. Manag. 21, 323-337.

Koehler, A.K, Sottocornola, M., Kiely, G., 2011. How strong is the current carbon sequestration of an Atlantic blanket bog?. Global Change Biol. 17, 309-319.

Kutzbach, L., Wagner, D., Pfeiffer, E.M., 2004. Effect of microrelief and vegetation on methane emission from wet polygonal tundra, Lena Delta, Northern Siberia. Biogeochemistry 69, 341-362.

Laanbroek, H.J. 2010. Methane emission from natural wetlands: interplay between emergent macrophytes and soil microbial processes. A mini-review. Ann. Bot. 105(1), 141-153.

Lai, D.Y.F., Moore, T.R., Roulet, N.T., 2014. Spatial and temporal variations of methane flux measured by autochambers in a temperate ombrotrophic peatland. J. Geophys. Res-Biogeo. 119, 864-880.

Laine, A., Wilson, D., Kiely, G., Bryne, K.A., 2007. Methane flux dynamics in an Irish lowland blanket bog. Plant Soil, 299, 181-193.

Lee, R.Y., Porubsky, W.P., Feller, I.C., McKee, K.L., Joye, S.B., 2008. Porewater biogeochemistry and soil metabolism in dwarf red mangrove habitats (Twin Cays, Belize). Biogeochemistry 87, 181-198.

Li, T.T., Xie, B.H., Wang, G.C., Zhang, W., Zhang, Q., Vesala, T., Raivonen, M., 2016. Field-scale simulation of methane emissions from coastal wetlands in China using an improved version of $\mathrm{CH}_{4} \mathrm{MOD}_{\text {wetland. }}$ Sci. Total Environ. 559, 256-267.

Liu, D.Y., Ding, W.X., Jia, Z.J., Cai, Z.C., 2011. Relation between methanogenic archaea and methane production potential in selected natural wetland ecosystems across China. Biogeosciences 8, 329-338.

Livesley, S.J., Andrusiak, S.M., 2012. Temperate mangrove and salt marsh sediments are a small methane and nitrous oxide source but important carbon store. Estuar. Coast. Shelf S. 97, 19-27.

Marín-Muñiz, J.L., Hernández, M.E., Moreno-Casasola, P., 2015. Greenhouse gas emissions from coastal freshwater wetlands in Veracruz Mexico: Effect of plant community and seasonal dynamics. Atmos. Environ. 107, 107-117.

Magenheimer, J.F., Moore, T.R., Chmura, G.L., Daoust, R.J., 1996. Methane and carbon dioxide flux from a macrotidal salt marsh, Bay of Fundy, New Brunswick. Estuaries 19, 139-145.

Molnar, N., Welsh, D.T., Marchand, C., Deborde, J., Meziane, T., 2013. Impacts of shrimp farm effluent on 
water quality, benthic metabolism and N-dynamics in a mangrove forest (New Caledonia). Estuar. Coast. Shelf S. 117, 12-21.

Moore, T.R., De Young, A., Bubier, J.L., Humphreys, E.R., Lafleur, P.M., Roulet, N.T., 2011. A multi-year record of methane flux at the Mer Bleue Bog, southern Canada. Ecosystems 14, 646-657.

Musavi, T., Migliavacca, M., Reichstein, M., Kattge, J., Wirth, C., Black, T.A., Janssens, I., Knohl, A., Loustau, D., Roupsard, O., Varlagin, A., Rambal, S., Cescatti, A., Gianelle, D., Kondo, H., Tamrakar, R., Mahecha, M.D., 2017. Stand age and species richness dampen interannual variation of ecosystem-level photosynthetic capacity. Nat. Ecol. Evol. 1, 0048.

Neubauer, S.C., Franklin, R.B., Berrier, D.J., 2013. Saltwater intrusion into tidal freshwater marshes alters the biogeochemical processing of organic carbon. Biogeosciences 10, 8171-8183.

Nilsson, M., Sagerfors, J., Buffam, I., Laudon, H., Eriksson, T., Grelle, A., Klemedtsson, L., Weslien, P., Lindroth, A., 2008. Contemporary carbon accumulation in a boreal oligotrophic minerogenic mire-a significant sink after accounting for all C-fluxes. Global Change Biol. 14, 2317-2332.

Olsson, L., Ye, S., Yu, X., Wei, M., Krauss, K.W., Brix, H., 2015. Factors influencing $\mathrm{CO}_{2}$ and $\mathrm{CH}_{4}$ emissions from coastal wetlands in the Liaohe Delta, Northeast China. Biogeosciences 12, 4965-4977.

Ortiz-Llorente, M.J., Alvarez-Cobelas, M., 2012. Comparison of biogenic methane emissions from unmanaged estuaries, lakes, oceans, rivers and wetlands. Atmos. Environ. 59, 328-337.

Poffenbarger, H.J., Needelman, B.A., Megonigal, J.P., 2011. Salinity influence on methane emissions from tidal marshes. Wetlands 31, 831-842.

Purdy, K., Nedwell, D., Embley, T., 2003. Analysis of the sulfate-reducing bacterial and methanogenic archaeal populations in contrasting Antarctic sediments. Applied and Environmental Microbiology, 69, 3181-3191.

Purvaja, R. \& Ramesh, R. 2001. Natural and anthropogenic methane emission from coastal wetlands of South India. Environ. Manage. 27, 547-557.

R Development Core Team. 2017. R: A language and Environment for Statistical Computing. R Foundation for Statistical Computing, Vienna. ISBN 3-900051-07-0. URL http://www.R-project.org [accessed 12 December 2017]

Rinne, J., Riutta, T., Pihlatie, M., Aurela, M., Haapanala, S., Tuovinen, J.P., Tuittila, E.S., Vesala, T., 2007. Annual cycle of methane emission from a boreal fen measured by the eddy covariance technique. Tellus B $59,449-457$.

Saarnio, S., Winiwarter, W., Leitão, J., 2009. Methane release from wetlands and watercourses in Europe. Atmos. Environ. 43, 1421-1429. 
Segers, R., 1998. Methane production and methane consumption: a review of processes underlying wetland methane fluxes. Biogeochemistry 41, 23-51.

Shannon, R.D., White, J.R., 1994. A three-year study of controls on methane emissions from two Michigan peatlands. Biogeochemistry 27, 35-60.

Shurpali, N.J., Verma, S.B., Clement, R.J., Billesbach, D.P., 1993. Seasonal distribution of methane flux in a Minnesota peatland measured by eddy correlation. J. Geophys. Res-Atmos. 98, 20649-20655.

Sinke, A.J.C., Cornelese, A.A., Cappenberg, T.E., Zehnder, A.J.B., 1992. Seasonal variation in sulfate reduction and methanogenesis in peaty sediments of eutrophic Lake Loosdrecht, The Netherlands. Biogeochemistry 16, 43-61.

Song, C.C., Xu, X.F., Tian, H.Q., Wang, Y.Y., 2009. Ecosystem-atmosphere exchange of $\mathrm{CH}_{4}$ and $\mathrm{N}_{2} \mathrm{O}$ and ecosystem respiration in wetlands in the Sanjiang Plain, Northeastern China. Global Change Biol. 15, 692-705.

Ström, L., Tagesson, T., Mastepanov, M., Christensen, T.R., 2012. Presence of Eriophorum scheuchzeri enhances substrate availability and methane emission in an Arctic wetland. Soil Biol. Biochem. 45, 61-70.

Sun, Z.G., Wang, L.L., Tian, H.Q., Jiang, H.H., Mou, X.J., Sun, W.L., 2013. Fluxes of nitrous oxide and methane in different coastal Suaeda salsa marshes of the Yellow River estuary, China. Chemosphere 90, $856-865$.

Tian, H.Q., Xu, X.F., Zhang, C., Ren, W., Chen, G.S., Liu, M.L., Lu, D.S., Pan, S.F., 2008. Forecasting and assessing the large-scale and long-term impacts of global environmental change on terrestrial ecosystems in the United States and China. In: Real World Ecology: Large-scale and Long-term Case Studies and Methods (eds Miao S, Carstenn S, Nungesser M), Springer, New York, USA.

Tong, C., Wang, W.Q., Zeng, C.S., Marrs, R., 2010. Methane $\left(\mathrm{CH}_{4}\right)$ emissions from a tidal marsh in the Min River estuary, southeast China. J. Environ. Sci. Heal. A 45, 506-516.

Tong, C., Wang, W.Q., Huang, J.F., Gauci, V., Zhang, L.H., Zeng, C.S., 2012. Invasive alien plants increase $\mathrm{CH}_{4}$ emissions from a subtropical tidal estuarine wetland. Biogeochemistry 111, 677-693.

Tong, C., Zhang, L.H., Wang, W.Q., Gauci, V., Marrs, R., Liu, B.G., Jia, R.X., Zeng, C.S., 2011. Contrasting nutrient stocks and litter decomposition in stands of native and invasive species in a sub-tropical estuarine marsh. Environ. Res. 111, 909-916.

Tong, C., Wang, C., Huang, J.F., Wang, W.Q., E, Y., Yao, C., 2015. Ecosystem respiration does not differ before and after tidal inundation in brackish marshes of the Min River estuary, southeast China. Wetlands 34, 225-233. 
Updegraff, K., Pastor, J., Bridgham, S.D., Johnston, C.A., 1995. Environmental and substrate controls over carbon and nitrogen mineralization in northern wetlands. Ecol. Appl. 5, 151-163.

van den Pol-van Dasselaar, A., Oenema, O., 1999. Methane production and carbon mineralisation of size and density fractions of peat soils. Soil Biol. Biochem. 31, 877-886.

van der Gon, H.A.D., van Bodegom, P.M., Wassmann, R., Lantin, R.S., Metra-Corton, T.M., 2001. Sulfate-containing amendments to reduce methane emissions from rice fields: mechanisms, effectiveness and costs. Mitig. Adapt. Strat. Gl. 6, 71-89.

Vizza, C., West, W.E., Jones, S.E., Hart, J.A., Lamberti G.A., 2017. Regulators of coastal wetland methane production and responses to simulated global change. Biogeosciences 14, 431-446.

Wachinger, G., Fiedler, S., Zepp, K., Gattinger, A., Sommer, M., Roth, K., 2000. Variability of sediment methane production on the micro-scale: spatial association with hot spots of organic material and Archaeal populations. Soil Biol. Biochem. 32, 1121-1130.

Walter, B.P., Heimann, M., Matthews, E., 2001. Modeling modern methane emissions from natural wetlands: 1. Model description and results. J. Geophys. Res-Atmos. 106, 34189-34206.

Wang, C., Lai, D.Y.F., Tong, C., Wang, W.Q., Huang, J.F., Zeng, C.S., 2015. Variations in temperature sensitivity $\left(Q_{10}\right)$ of $\mathrm{CH}_{4}$ emission from a subtropical estuarine marsh in southeast China. PLOS ONE, 10(5), e0125227.

Wang, H.T., Liao, G.S., Souza, M.D., Yu, X.Q., Yang, J., Yang, X.R., Zheng, T.L., 2016. Temporal and spatial variations of greenhouse gas fluxes from a tidal mangrove wetland in Southeast China. Environ. Sci. Pollut. R. 23, 1873-1885.

Wassmann, R., Neue, H.U., Bueno, C., Lantin, R.S., Alberto, M.C.R., Buendia, L.V., Bronson, K., Papen, H., Rennenberg, H., 1998. Methane production capacities of different rice soils derived from inherent and exogenous substrates. Plant Soil, 203, 227-237.

Wei, D., Wang, X.D., 2017. Uncertainty and dynamics of natural wetland $\mathrm{CH}_{4}$ release in China: Research status and priorities. Atmos. Environ. 154, 95-105.

Welti, N., Hayes, M., Lockington, D., 2017. Seasonal nitrous oxide and methane emissions across a subtropical estuarine salinity gradient. Biogeochemistry 132, 55-69.

Whalen, S.C. 2005. Biogeochemistry of methane exchange between natural wetlands and the atmosphere. Environ. Eng. Sci. 22, 73-94.

Whiting, G.J., Chanton, J.P., 1993. Primary production control of methane emission from wetlands. Nature 364, 794-795. 
World Meteorological Organization, 2016. WMO Greenhouse Gas Bulletin No.12 (October 2016). https://library.wmo.int/opac/doc_num.php?explnum_id=3084.pdf.

Xiang, J., Liu, D.Y., Ding, W.X., Yuan, J.J., Lin, Y.X., 2015. Invasion chronosequence of Spartina alterniflora on methane emission and organic carbon sequestration in a coastal salt marsh. Atmos. Environ. 112, $72-80$.

Yvon-Durocher, G., Allen, A.P., Bastviken, D., Conrad, R., Gudasz, C., St-Pierre, A., Thanh-Duc, N., del Giorgio, P.A., 2014. Methane fluxes show consistent temperature dependence across microbial to ecosystem scales. Nature 507, 488-491.

Zhang, Y.H., Ding, W.X., Cai, Z.C., Valerie, P., Han, F.X., 2010. Response of methane emission to invasion of Spartina alterniflora and exogenous $\mathrm{N}$ deposition in the coastal salt marsh. Atmos. Environ. 44, 4588-4594. 


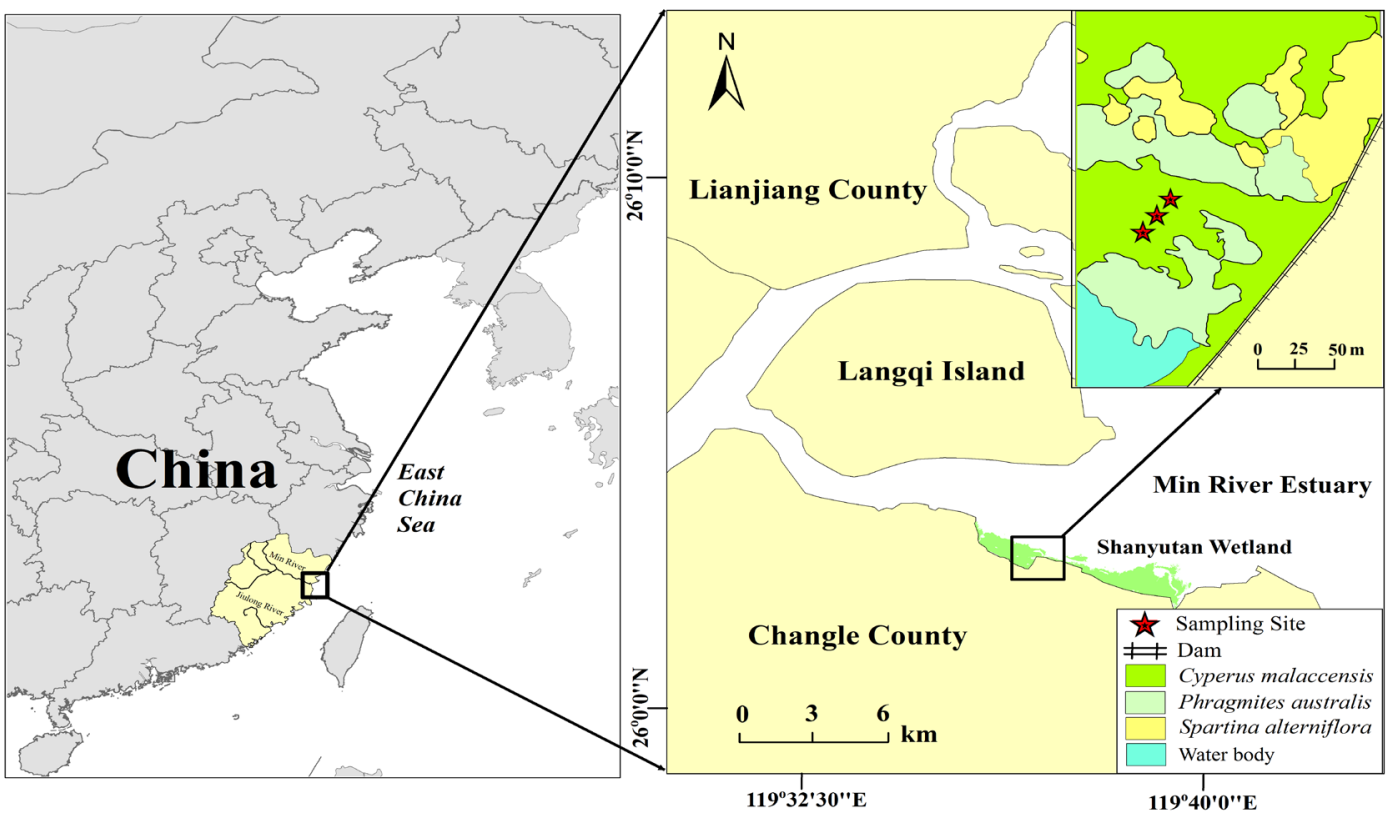

2 Fig. 1. Locations of the sampling sites in the subtropical brackish C. malaccensis 3 marsh ecosystem in the Min River estuary. 

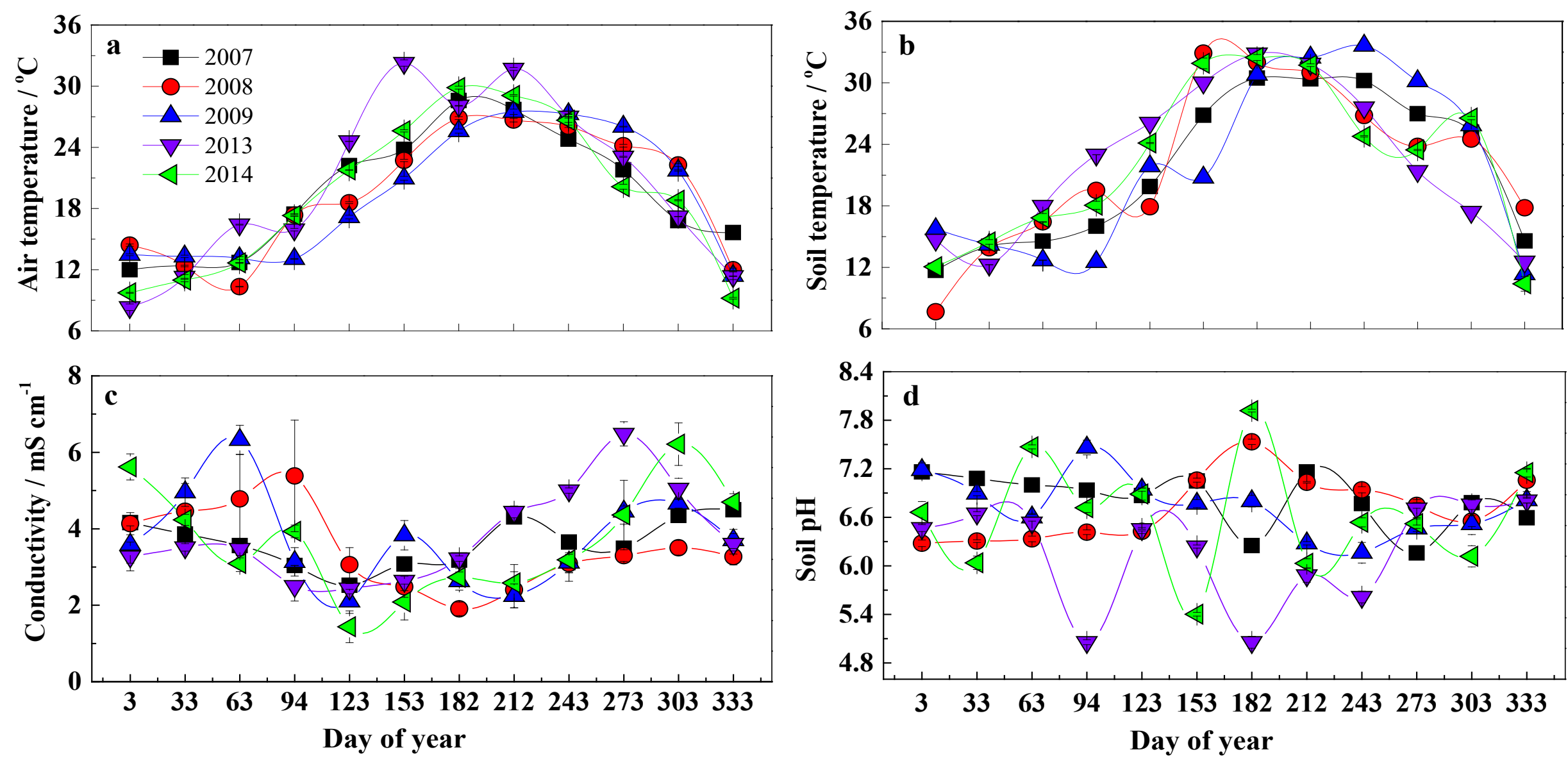

Fig. 2. Temporal variations in (a) air temperature, (b) soil temperature, (c) soil electrical conductivity, and (d) soil $\mathrm{pH}$ at the top $25 \mathrm{~cm}$ depth in

6 the brackish $C$. malaccensis marsh over the five-year study period. Values are means \pm 1 S.E. $(n=3)$. 


\section{$\log _{10}$ Anaerobic $\mathrm{CH}_{4}$ production / $\mu \mathrm{g} \mathrm{g}^{-1} \mathrm{~d}^{-1}$}

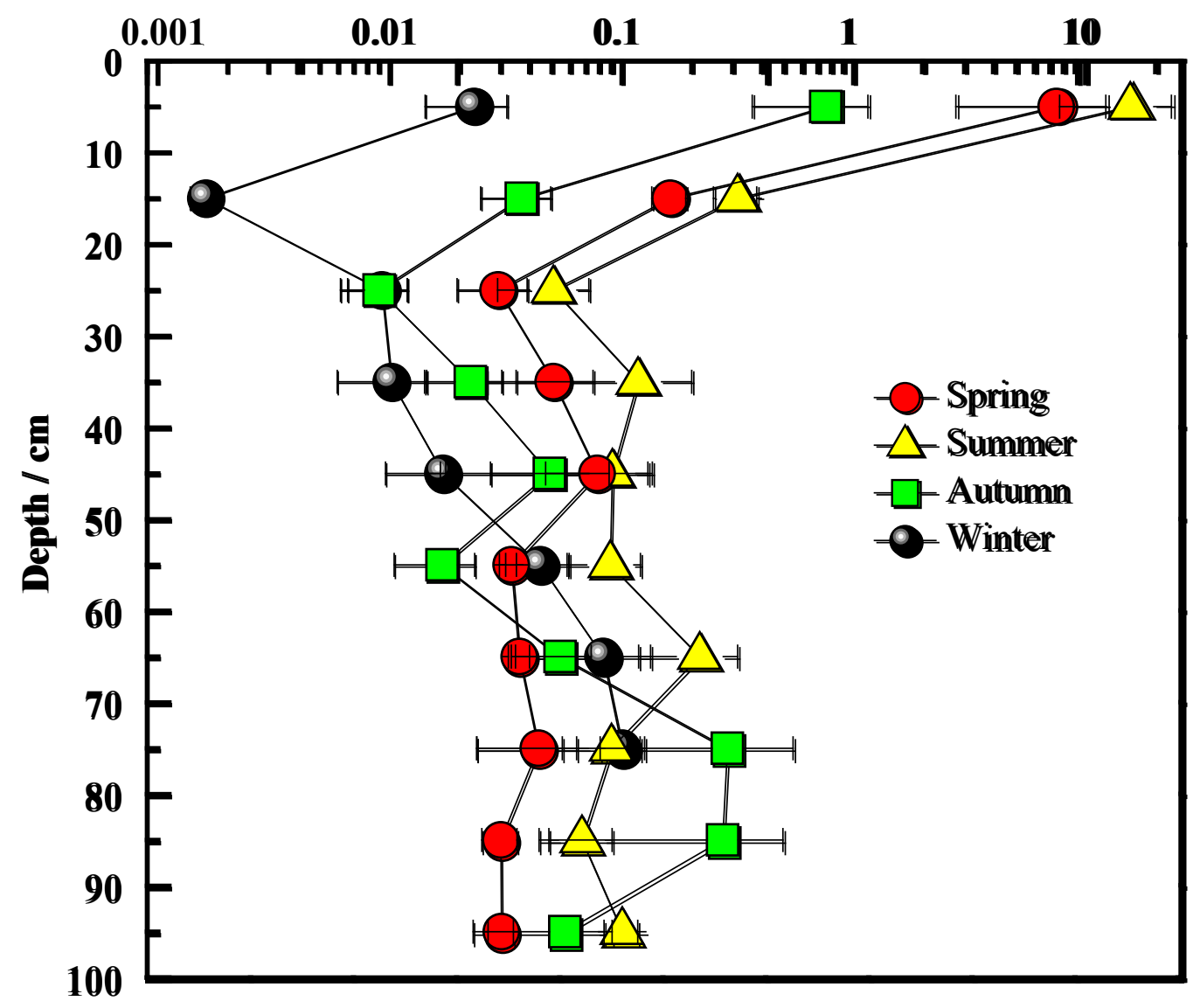

8 Fig. 3. Vertical profiles of $\mathrm{CH}_{4}$ production rates in the top $100 \mathrm{~cm}$ soils of the brackish

9 C. malaccensis marsh among the four seasons in 2012. Values are means \pm 1 S.E. $(n=$ $103)$. 
Porewater dissolved $\mathrm{CH}_{4}$ concentration / $\mathrm{\mu mol} \mathrm{L}^{-11}$

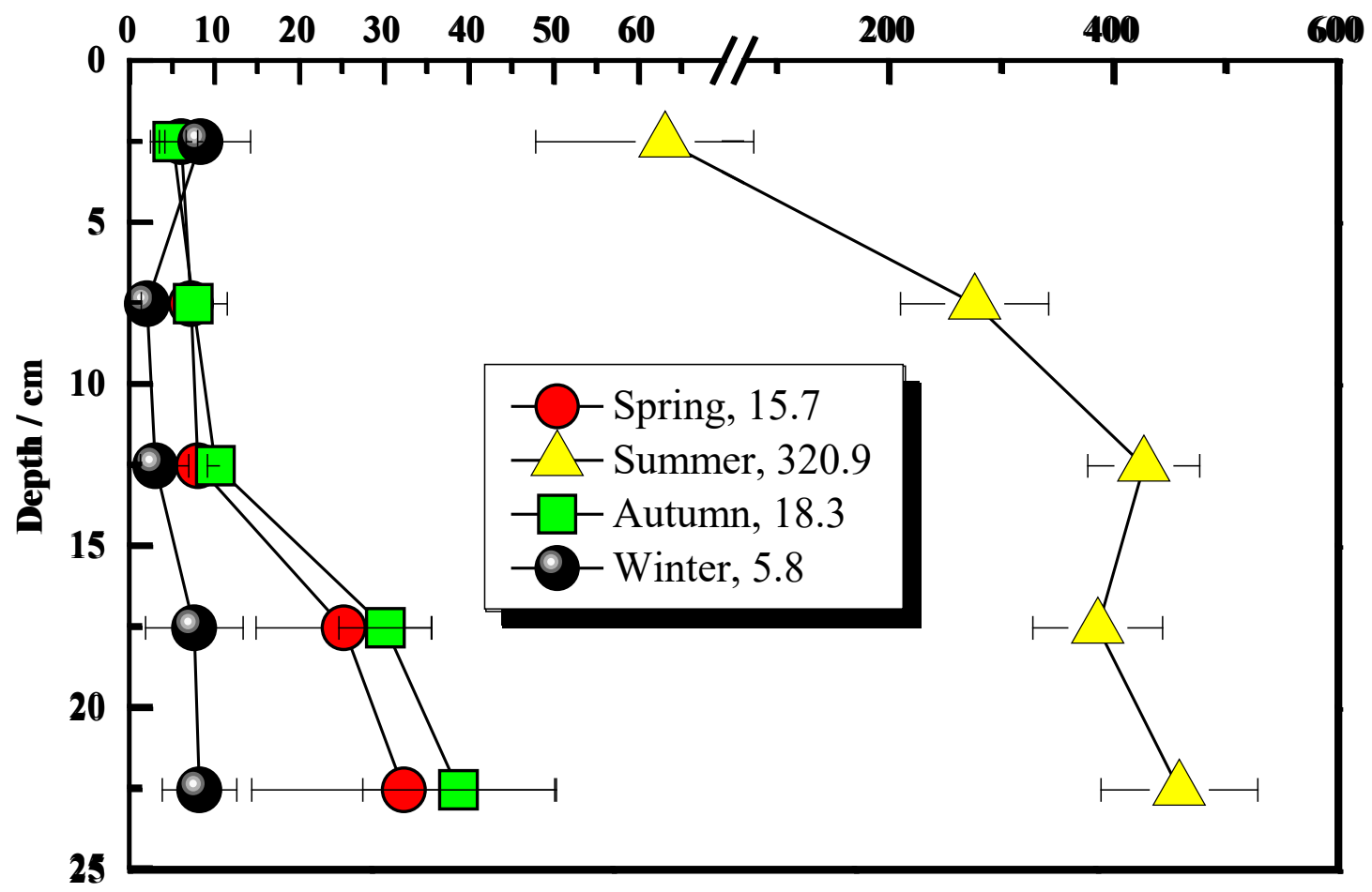

12 Fig. 4. Seasonal variations in porewater $\mathrm{CH}_{4}$ concentrations in the brackish $C$.

13 malaccensis marsh in 2012-2013. The numbers next to the symbols in the figure

14 legend represent the mean porewater $\mathrm{CH}_{4}$ concentrations in the top $25 \mathrm{~cm}$ soils.

15 Values are means \pm 1 S.E. $(n=12)$. 

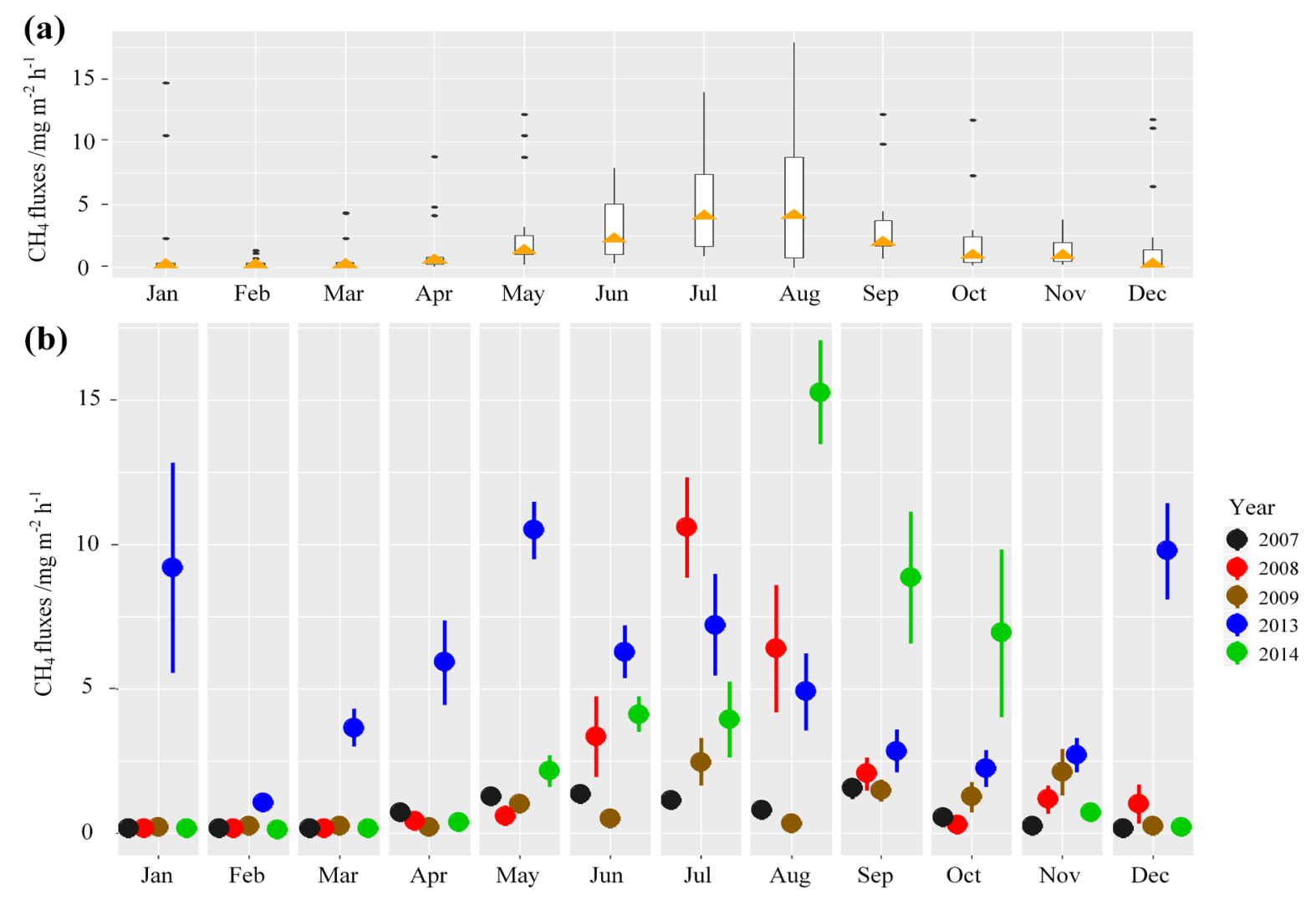

17 Fig. 5. (a) Monthly variations in average $\mathrm{CH}_{4}$ emissions in the brackish $C$.

18 malaccensis marsh over the five-year period. Box plots show the median (triangle),

19 25-75th percentile (limits), minimum and maximum values without outliers

20 (whiskers), and outliers (black dots). (b) Monthly variations in $\mathrm{CH}_{4}$ emissions in the

21 brackish marsh in individual years. The dots and bars represent the means and

22 standard errors, respectively. 


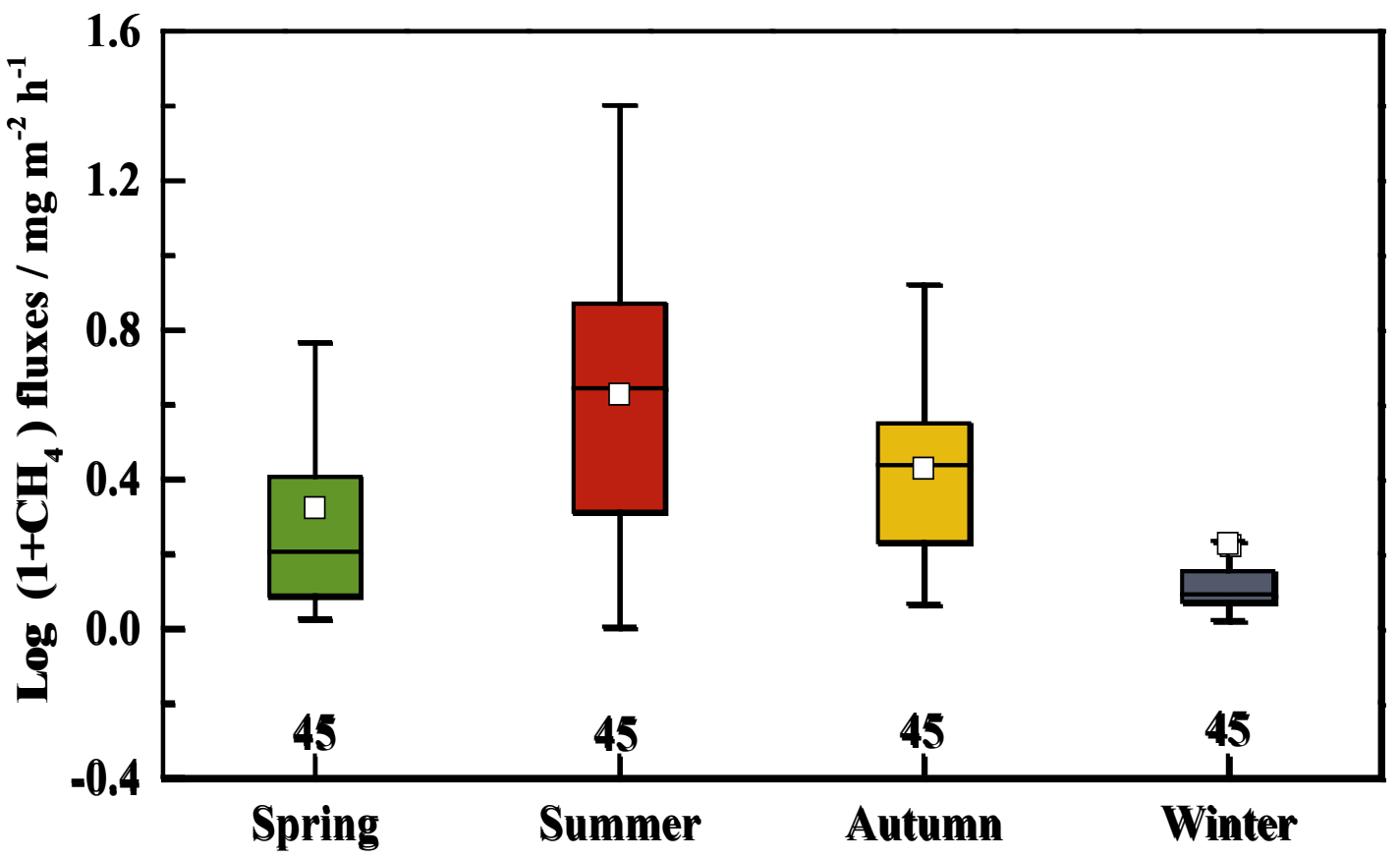

24 Fig. 6. Boxplots of seasonal variations in $\mathrm{CH}_{4}$ emissions in the brackish $C$.

25 malaccensis marsh over the study period. The boxes show the quartiles and median,

26 while the squares and whiskers represent the means and values within 1.5 times of the

27 interquartile range, respectively. The numbers above the $\mathrm{x}$-axis labels represent the

28 number of measurements in each season. 
a

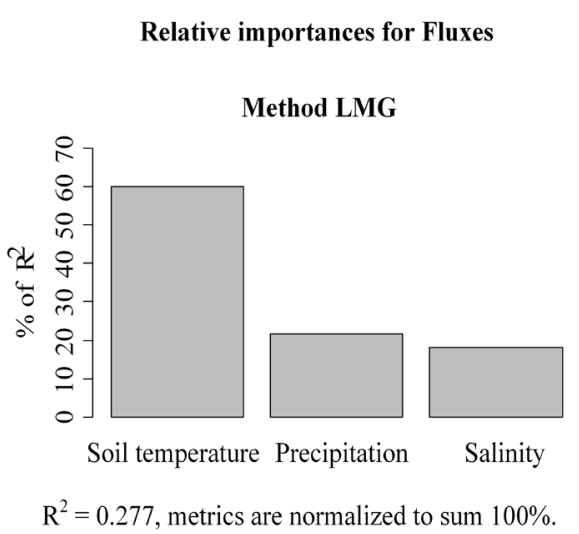

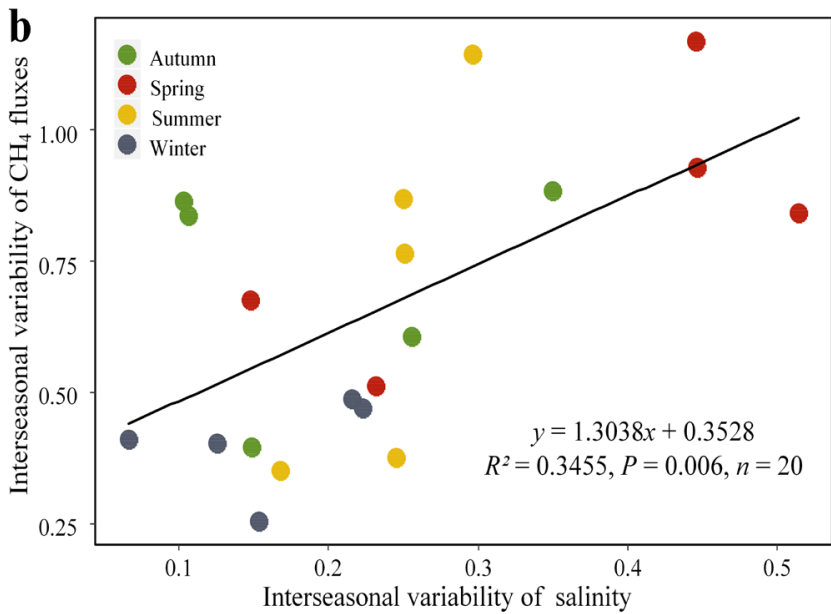

Fig. 7. (a) Relative importance of the three significant factors (soil temperature, precipitation and salinity) governing $\mathrm{CH}_{4}$ fluxes. The $\mathrm{R}^{2}$ value of 0.277 represented the proportion of variance explained by the fitted model, with the metrics being forced to sum to $100 \%$ using the R package of relaimpo and the command "rela=TRUE"; (b) The relationship between interseasonal variability of salinity and that of $\mathrm{CH}_{4}$ fluxes. The inter-seasonal variability of salinity and $\mathrm{CH}_{4}$ fluxes was computed by dividing the standard deviation by the mean. 


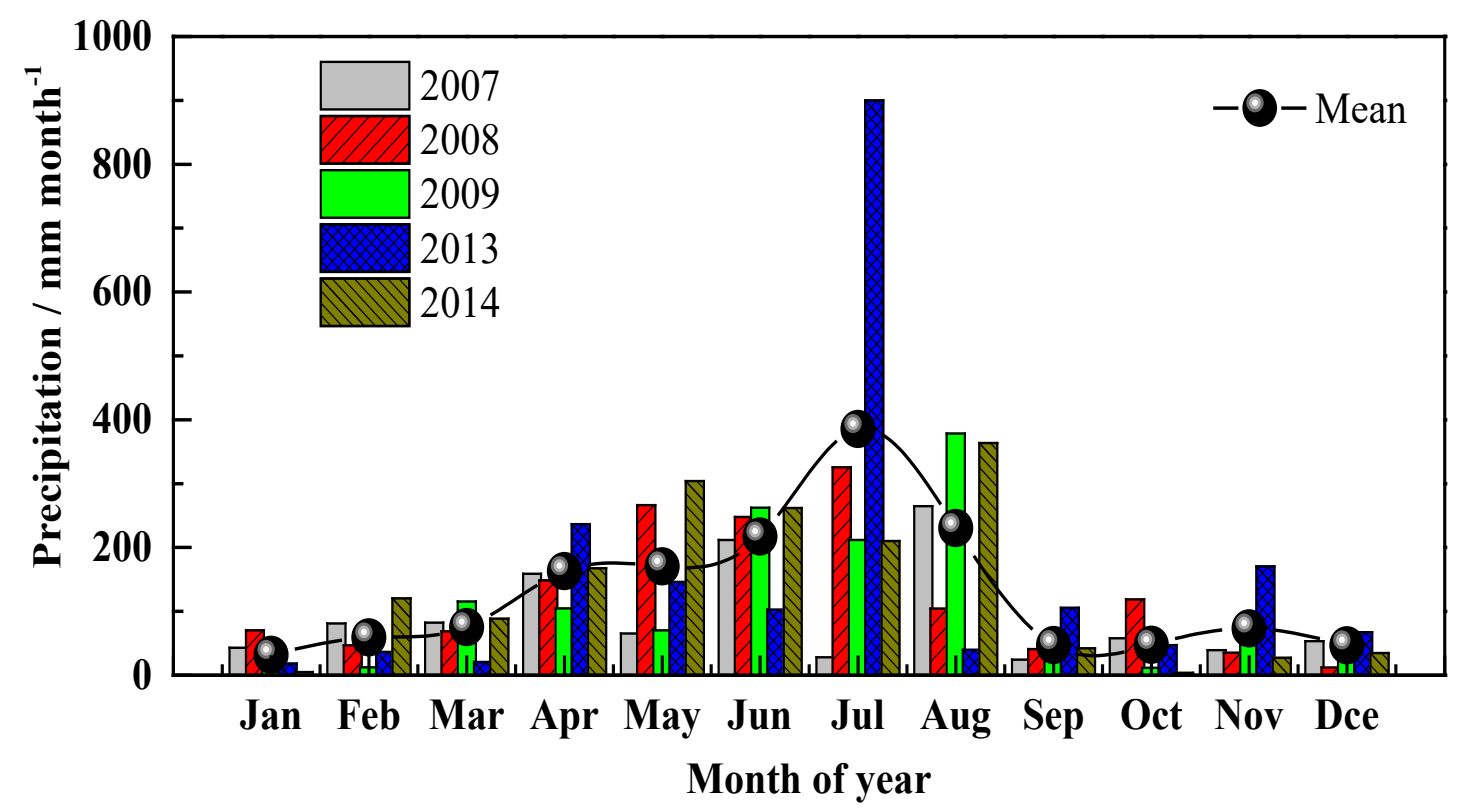

Fig. S1. Monthly precipitation in 2007-2009 and 2013-2014 for the Min River Estuary Station (mean represents the average for 2007-2009 and 2013-2014). 

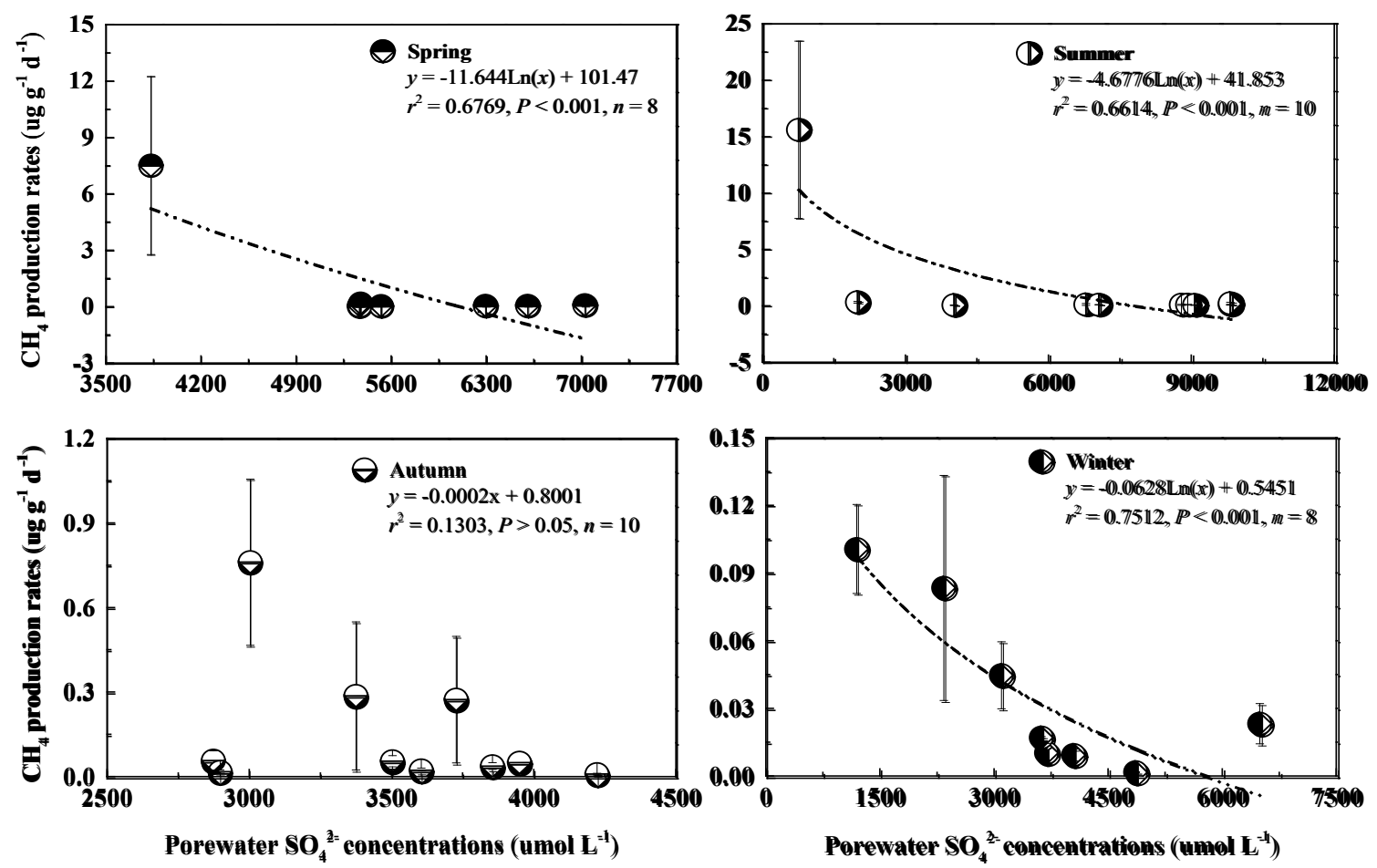

42 Fig. S2. Regression and significance analysis between profiles of $\mathrm{CH}_{4}$ production rate $(y)$ and 43 porewater $\mathrm{SO}_{4}{ }^{2-}$ concentration $(x)$ in the brackish C. malaccensis marsh for 2012. The soil 44 porewater $\mathrm{SO}_{4}{ }^{2-}$ concentrations during summer and autumn were for the depth of $0-100 \mathrm{~cm}(n=$ 45 10). The soil porewater $\mathrm{SO}_{4}{ }^{2-}$ concentrations during spring and winter were for the depth of $0-80$ $46 \mathrm{~cm}(n=8) . \mathrm{CH}_{4}$ production rates and porewater $\mathrm{SO}_{4}{ }^{2-}$ concentrations in each soil depth were the 47 averaged values of three sampling sites. 


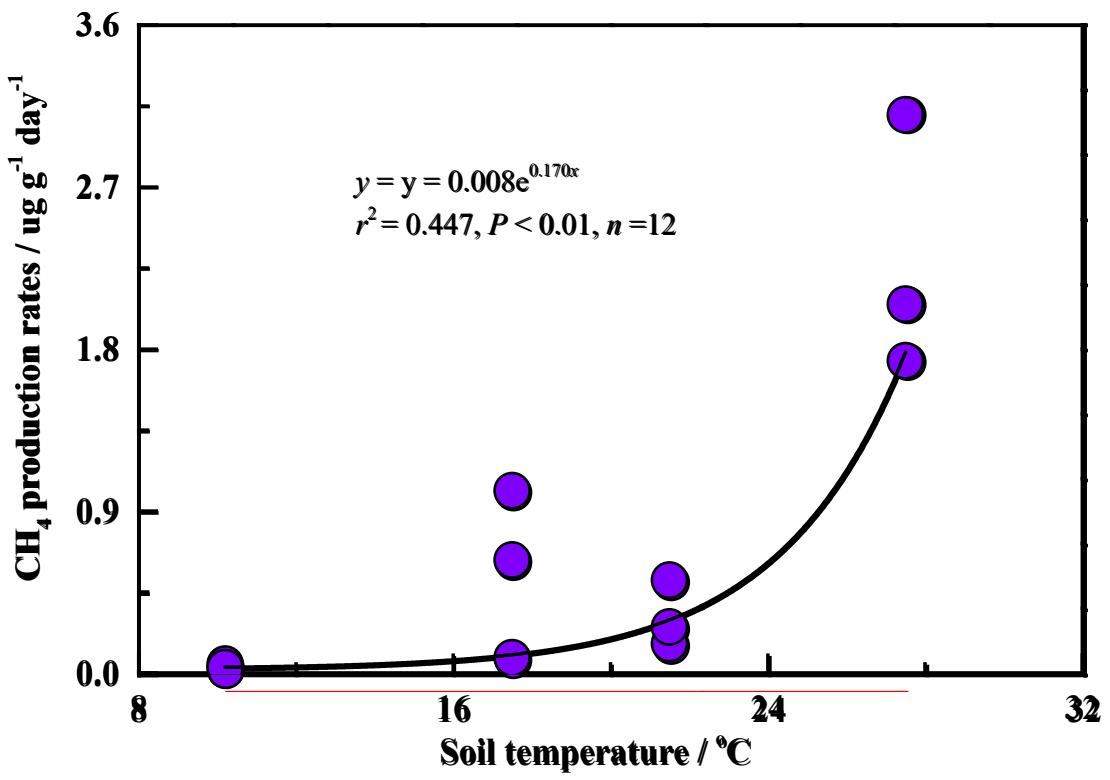

49 Fig. S3. Relationship between the average seasonal $\mathrm{CH}_{4}$ production rates at five depths and soil temperature in the brackish C. malaccensis marsh for 2012. 

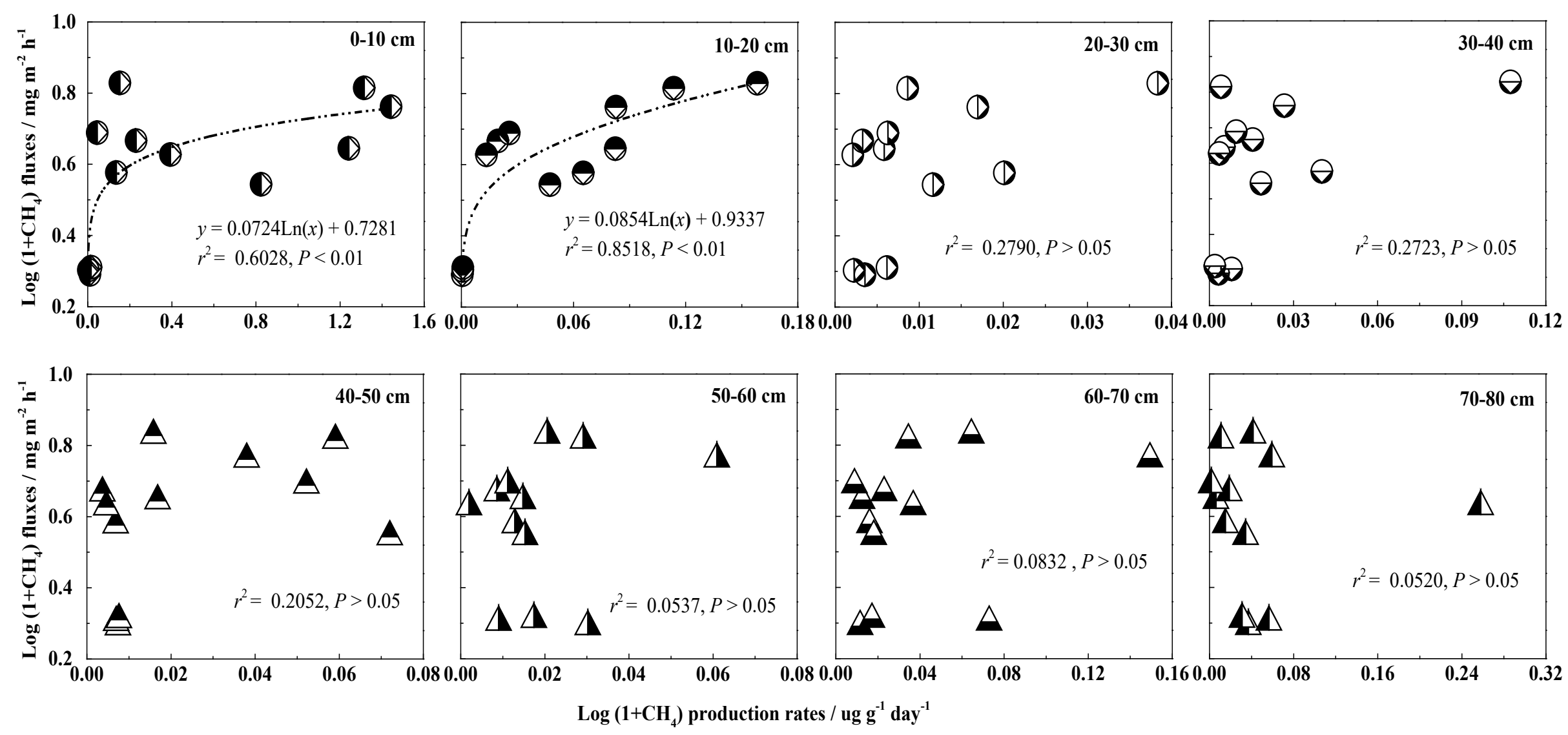

Fig. S4. Relationship between seasonal mean $\mathrm{CH}_{4}$ emissions and soil $\mathrm{CH}_{4}$ production rate at different depths in the brackish C. malaccensis marsh. 


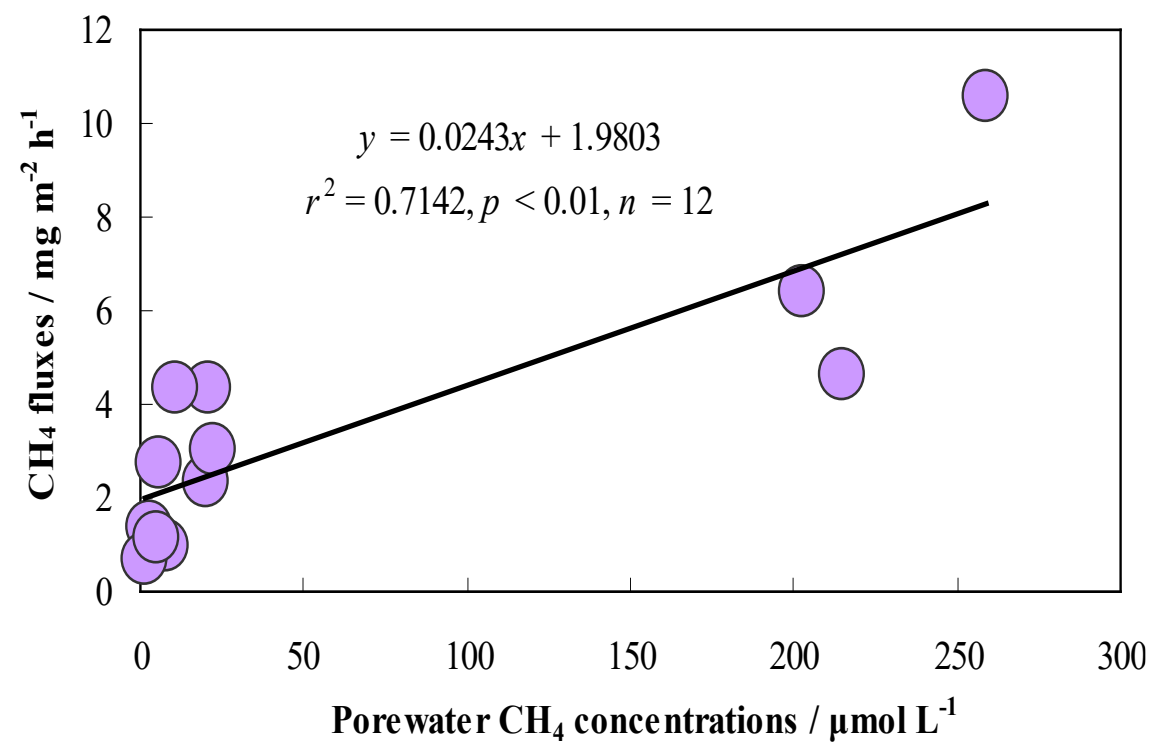

53

54 Fig. S5. Relationship between seasonal mean $\mathrm{CH}_{4}$ emissions and mean porewater $\mathrm{CH}_{4}$ 55 concentration in the brackish C. malaccensis marsh for 2013. (12 samples $=1$ average value at 56 five depths $\times 3$ sites $\times 4$ seasons $)$. 


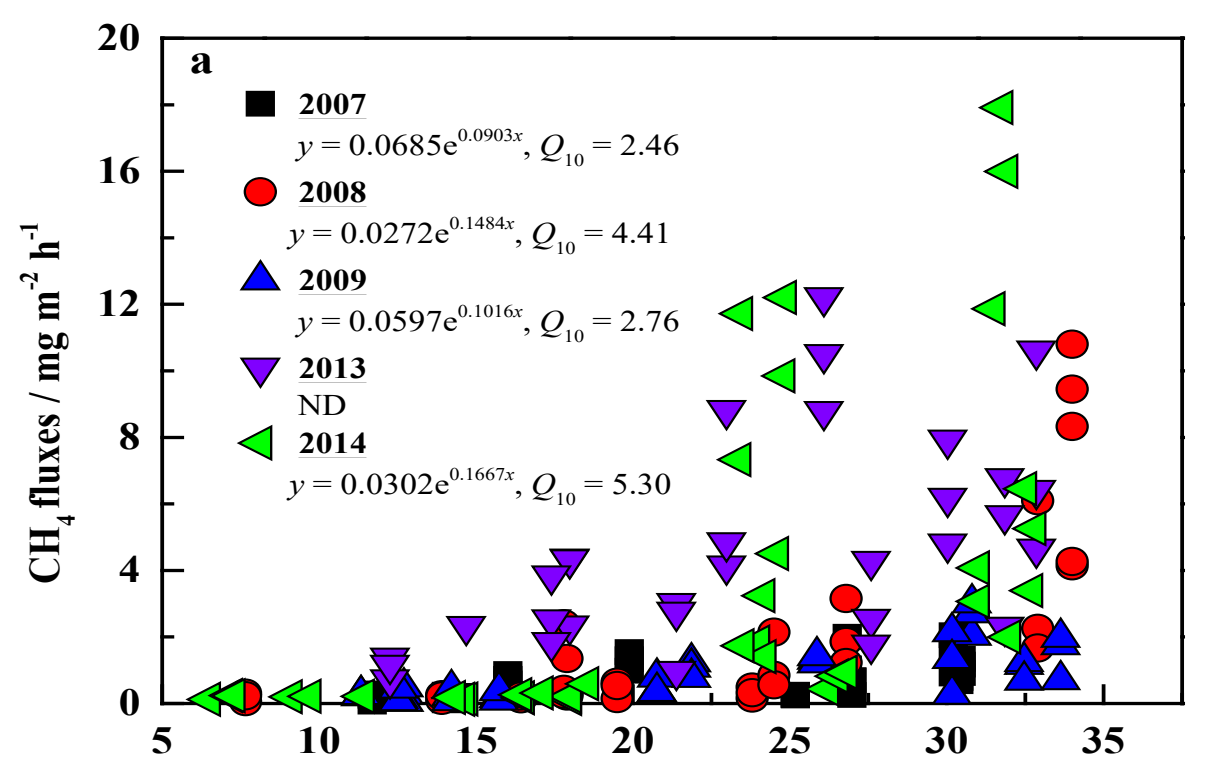

Air temperature / ${ }^{\circ} \mathrm{C}$

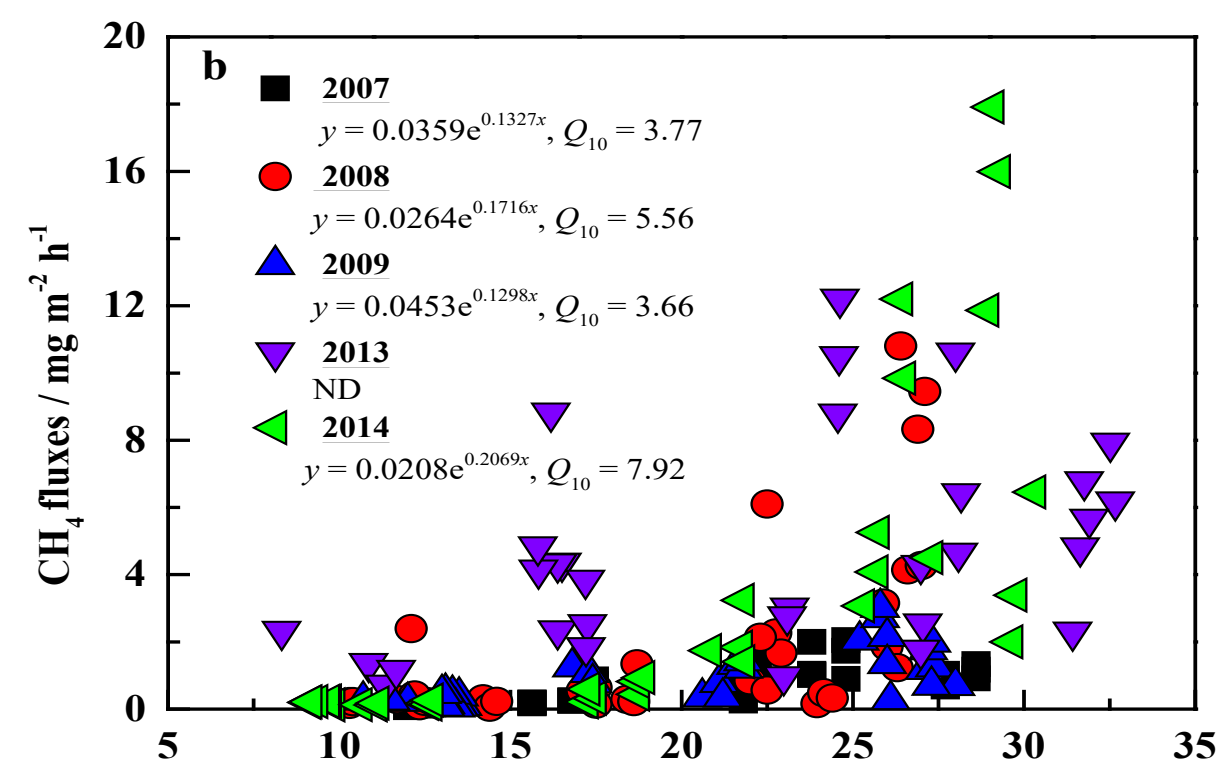

Soil temperature $/{ }^{\circ} \mathrm{C}$

Fig. S6. Relationships between $\mathrm{CH}_{4}$ emissions and air temperature $\left({ }^{\circ} \mathrm{C}\right)$ or soil temperature at the surface soil $(0-25 \mathrm{~cm})$ in the brackish $C$. malaccensis marsh from 2007 to 2008 and 2013 to 2014, as described by the exponential function $(P<0.05) . n=36$ for air temperature, soil temperature and $\mathrm{CH}_{4} \mathrm{emissions}$ of each year. ND means "no significant relationship". 


\section{$1 \quad$ Table 1}

2 Mean, minimum, and maximum values for the selected environmental variables and

$3 \mathrm{CH}_{4}$ emissions in the brackish C. malaccensis marsh from 2007 to 2008 and 2013 to

42014.

\begin{tabular}{|c|c|c|c|c|c|}
\hline & 2007 & 2008 & 2009 & 2013 & 2014 \\
\hline \multicolumn{6}{|l|}{ Air temperature $/{ }^{\circ} \mathrm{C}$} \\
\hline Minimum $^{\mathrm{a}}$ & $11.70 \pm 0.00$ & $7.66 \pm 0.06$ & $12.53 \pm 0.00$ & $12.26 \pm 0.00$ & $10.40 \pm 0.72$ \\
\hline Mean $^{\mathrm{b}}$ & $21.74 \pm 2.11$ & $22.02 \pm 2.26$ & $21.84 \pm 2.45$ & $22.30 \pm 2.14$ & $22.24 \pm 2.25$ \\
\hline Maximum $^{\mathrm{a}}$ & $30.47 \pm 0.00$ & $32.90 \pm 0.00$ & $33.63 \pm 0.03$ & $32.9 \pm 0.00$ & $32.5 \pm 0.00$ \\
\hline \multicolumn{6}{|l|}{ Soil temperature $/{ }^{\circ} \mathrm{C}$} \\
\hline Minimum $^{\mathrm{a}}$ & $12.00 \pm 0.00$ & $10.33 \pm 0.03$ & $11.40 \pm 0.38$ & $8.31 \pm 0.33$ & $9.20 \pm 0.08$ \\
\hline Mean $^{\mathrm{b}}$ & $19.65 \pm 1.72$ & $19.48 \pm 1.76$ & $19.22 \pm 1.82$ & $20.60 \pm 2.39$ & $19.32 \pm 2.17$ \\
\hline Maximum $^{\mathrm{a}}$ & $28.60 \pm 0.00$ & $26.87 \pm 0.15$ & $27.50 \pm 0.26$ & $32.27 \pm 0.32$ & $29.86 \pm 0.15$ \\
\hline \multicolumn{6}{|l|}{ Conductivity / $\mathrm{mS} \mathrm{cm}^{-1}$} \\
\hline Minimum $^{\mathrm{a}}$ & $2.52 \pm 0.00$ & $1.91 \pm 0.18$ & $2.10 \pm 0.32$ & $2.43 \pm 0.13$ & $1.44 \pm 0.42$ \\
\hline Mean $^{\mathrm{b}}$ & $3.64 \pm 0.18$ & $3.48 \pm 0.30$ & $3.73 \pm 0.35$ & $3.80 \pm 0.35$ & $3.68 \pm 0.41$ \\
\hline Maximum $^{\mathrm{a}}$ & $4.50 \pm 0.00$ & $5.38 \pm 1.46$ & $6.33 \pm 0.38$ & $6.48 \pm 0.32$ & $6.22 \pm 0.56$ \\
\hline \multicolumn{6}{|l|}{ pH } \\
\hline Minimum $^{\mathrm{a}}$ & $6.25 \pm 0.00$ & $6.28 \pm 0.04$ & $6.16 \pm 0.13$ & $5.06 \pm 0.03$ & $5.40 \pm 0.02$ \\
\hline Mean $^{\mathrm{b}}$ & $6.82 \pm 0.10$ & $6.72 \pm 0.12$ & $6.74 \pm 0.11$ & $6.19 \pm 0.18$ & $6.62 \pm 0.20$ \\
\hline Maximum $^{\mathrm{a}}$ & $7.16 \pm 0.00$ & $7.53 \pm 0.03$ & $7.46 \pm 0.09$ & $6.76 \pm 0.06$ & $7.92 \pm 0.06$ \\
\hline \multicolumn{6}{|l|}{$\mathrm{CH}_{4}$ flux / $\mathrm{mg} \mathrm{m}^{-2} \mathrm{~h}^{-1}$} \\
\hline Minimum $^{\mathrm{a}}$ & $0.19 \pm 0.07$ & $0.19 \pm 0.07$ & $0.22 \pm 0.08$ & $1.07 \pm 0.19$ & $0.20 \pm 0.04$ \\
\hline Mean $^{\mathrm{b}}$ & $0.71 \pm 0.15$ & $2.50 \pm 1.17$ & $0.87 \pm 0.23$ & $5.10 \pm 0.60$ & $3.86 \pm 1.44$ \\
\hline Maximum $^{\mathrm{a}}$ & $1.56 \pm 0.34$ & $13.99 \pm 5.11$ & $2.47 \pm 0.82$ & $10.49 \pm 0.98$ & $15.92 \pm 2.80$ \\
\hline $\begin{array}{l}\text { Cumulative emissions / g } \mathrm{CH}_{4} \\
\mathbf{m}^{-2}\end{array}$ & 6.19 & 22.14 & 7.68 & 48.86 & 34.13 \\
\hline
\end{tabular}

$5 \quad{ }^{a}$ Values are means $( \pm$ S.E. $)$ of samples $(n=3)$ measured from the brackish $C$. malaccensis marsh

6 over all sampling sites. ${ }^{\mathrm{b}}$ Values are means $( \pm$ S.E.) of samples $(n=36)$ measured from the brackish

$7 \quad$ C. malaccensis marsh over all sampling sites and sampling periods. 
Table 2

9 Summary of two-way analysis of variance ANOVA (season and depth as factors and the sulfate $\left(\mathrm{SO}_{4}{ }^{2-}\right.$ ) concentrations as covariates) models

10 fitted the effect of season, soil depth and their interaction on the $\mathrm{CH}_{4}$ production rates and porewater $\mathrm{CH}_{4}$ concentrations in the $C$. malaccensis

11 marsh.

\begin{tabular}{|c|c|c|c|c|c|c|c|c|c|c|}
\hline & \multicolumn{5}{|c|}{$\mathrm{CH}_{4}$ production rate } & \multicolumn{5}{|c|}{ Porewater $\mathrm{CH}_{4}$ concentration } \\
\hline & $d f$ & Sum of squares & Mean square & $F$ values & $P$ values & $d f$ & Sum of squares & Mean square & $F$ values & $P$ values \\
\hline Season & 3 & 9.11 & 3.0366 & 15.918 & $<0.001$ & 3 & 29.366 & 9.789 & 90.2 & $<0.001$ \\
\hline Soil depth & 9 & 11.963 & 1.3292 & 6.968 & $<0.001$ & 4 & 3.533 & 0.883 & 8.139 & $<0.001$ \\
\hline $\mathrm{SO}_{4}{ }^{2-}$ concentration & 1 & 2.412 & 2.4119 & 12.643 & $<0.001$ & 1 & 0.048 & 0.048 & 0.439 & 0.512 \\
\hline Season $\times$ soil depth & 23 & 10.232 & 0.4448 & 2.332 & 0.003 & 12 & 1.777 & 0.148 & 1.365 & 0.224 \\
\hline Residuals & 71 & 13.544 & 0.1908 & & & 39 & 4.232 & 0.109 & & \\
\hline
\end{tabular}

12 Note: both the data of the $\mathrm{CH}_{4}$ production rates and porewater $\mathrm{CH}_{4}$ concentrations were log-transformed to meet the homogeneity of variances. 


\section{$13 \quad$ Table 3}

14 (a) Summary of linear mixed model fitted for $\mathrm{CH}_{4}$ fluxes accounting for random site effect and temporal autocorrelations, and (b) summary of 15 linear mixed model fitted for interseasonal variability of $\mathrm{CH}_{4}$ fluxes accounting for repeated measurement among different years. Models are 16 ranked in order of the lowest Akaike information criterion corrected for low samples sizes (AIC) along with delta AIC. The predictors of the best 17 model with lowest AIC were tested by Type II Wald test and the significant positive $(\uparrow)$ or negative effects $(\downarrow)$ of chosen continuous predictors 18 are indicated.

\begin{tabular}{|c|c|c|c|c|c|c|c|}
\hline & AIC & delta AIC & Step & $d f$ & Deviance & Residual $d f$ & Residual deviance \\
\hline \multicolumn{8}{|l|}{ (a) } \\
\hline \multicolumn{8}{|l|}{$\mathrm{CH}_{4}$ fluxes } \\
\hline Soil temperature + Precipitation + Salinity & 907.28 & 0.00 & - Air temperature & 1 & 1.30 & 173 & 860.84 \\
\hline Air temperature + Soil temperature + Precipitation + Salinity & 912.62 & 5.34 & $-\mathrm{pH}$ & 1 & 0.36 & 172 & 859.54 \\
\hline Air temperature + Soil temperature + Precipitation $+\mathrm{pH}+$ Salinity & 918.89 & 11.61 & - Year & 4 & 13.97 & 171 & 859.18 \\
\hline Year + Air temperature + Soil temperature + Precipitation $+\mathrm{pH}+$ Salinity & 931.45 & 24.17 & - Season & 3 & 1.68 & 167 & 845.20 \\
\hline $\begin{array}{l}\text { Year }+ \text { Season }+ \text { Air temperature }+ \\
\text { Soil temperature }+ \text { Precipitation }+\mathrm{pH}+\text { Salinity }\end{array}$ & 949.68 & 42.4 & & & & 164 & 843.52 \\
\hline Predictors from best model tested & & & & & & $F$ values & $P$ values \\
\hline Soil temperature $(\uparrow)$ & & & & 1 & & 17.36 & $<0.001$ \\
\hline Precipitation $(\uparrow)$ & & & & 1 & & 8.58 & $<0.001$ \\
\hline Salinity $(\downarrow)$ & & & & 1 & & 5.92 & 0.0149 \\
\hline \multicolumn{8}{|l|}{ (b) } \\
\hline Interseasonal variability & AIC & delta AIC & Step & $d f$ & Deviance & Residual $d f$ & Residual deviance \\
\hline Salinitycv & 21.73 & 0.00 & - Air temperature $\mathrm{cv}_{\mathrm{c}}$ & 1 & 2.36 & 16 & -4.80 \\
\hline Air temperature ${ }_{c v}+$ Salinity $_{\mathrm{cv}}$ & 26.01 & 4.28 & $-\mathrm{pH}_{\mathrm{cv}}$ & 1 & 1.72 & 15 & -7.16 \\
\hline
\end{tabular}




\begin{tabular}{|c|c|c|c|c|c|c|c|}
\hline Air temperature ${ }_{\mathrm{cv}}+\mathrm{pH}_{\mathrm{cv}}+$ Salinity $_{\mathrm{cv}}$ & 30.93 & 9.20 & - Precipitation ${ }_{\mathrm{cv}}$ & 1 & 0.82 & 14 & -8.88 \\
\hline Air temperature ${ }_{\mathrm{cv}}+$ Precipitation $_{\mathrm{cv}}+\mathrm{pH}_{\mathrm{cv}}+$ Salinity $_{\mathrm{cv}}$ & 36.74 & 15.00 & - Soil temperature ${ }_{\mathrm{cv}}$ & 1 & 0.47 & 13 & -9.70 \\
\hline $\begin{array}{l}\text { Air temperature }{ }_{\mathrm{cv}}+ \\
\text { Soil temperature }{ }_{\mathrm{cv}}+\text { Precipitation }_{\mathrm{cv}}+\mathrm{pH}_{\mathrm{cv}}+\text { Salinitycv }_{\mathrm{cv}}\end{array}$ & 42.91 & 21.18 & & & & 12 & -10.17 \\
\hline Predictors from best model tested & & & & & & $F$ values & $P$ values \\
\hline $\operatorname{Salinitycv}_{(\uparrow)}$ & & & & 1 & & 10.56 & 0.001 \\
\hline
\end{tabular}


Table 4

20 Pearson correlation analysis between $\mathrm{CH}_{4}$ emissions and environmental variables in

21 the brackish C. malaccensis marsha . NS means "no significant relationship". Bold

22 numbers denote correlation coefficients for significant relationships.

\begin{tabular}{|c|c|c|c|c|c|c|}
\hline \multirow{2}{*}{ Environmental variables } & \multicolumn{6}{|c|}{$\mathrm{CH}_{4}$ fluxes $\left(\mathrm{mg} \mathrm{m}^{-2} \mathrm{~h}^{-1}\right)$} \\
\hline & 2007 & 2008 & 2009 & 2013 & 2014 & All years \\
\hline Precipitation $\left(\mathrm{mm}\right.$ month $\left.^{-1}\right)$ & $0.339 *$ & $0.517 * *$ & NS & NS & $0.403 *$ & $0.286 * *$ \\
\hline Air temperature $\left({ }^{\circ} \mathrm{C}\right)$ & $0.613 * *$ & $0.609 * *$ & $0.750 * *$ & NS & $0.581 * *$ & $0.373 * *$ \\
\hline Soil temperature $\left({ }^{\circ} \mathrm{C}\right)$ & $0.738 * *$ & $0.510 * *$ & $0.711 * *$ & NS & $0.680 * *$ & $0.349 * *$ \\
\hline Soil pH & NS & $0.679 * *$ & $-0.427 * *$ & NS & NS & NS \\
\hline Soil conductivity $\left(\mathrm{mS} \mathrm{cm}^{-1}\right)$ & $-0.572 * *$ & $-0.409 *$ & $-0.384 *$ & $-0.456 * *$ & $-0.334 *$ & $-0.305 * *$ \\
\hline
\end{tabular}

23 a $n=36$ for environmental variables and $\mathrm{CH}_{4}$ emissions of each year from the Cyperus 24 malaccensis marsh. The symbols * and ** indicate significant correlations at the 0.05 and 0.01 25 levels, respectively. 


\section{Supporting Information}

\section{Title: Methane dynamics in an estuarine brackish Cyperus}

malaccensis marsh: Production and porewater concentration in soils, and net emissions to the atmosphere over five years

P. Yang ${ }^{\mathrm{a}, \mathrm{b}, \mathrm{c}}$, M. H. Wanga,b, Derrick Y.F. Lai ${ }^{\mathrm{d}, *}$, K. P. Chun ${ }^{\mathrm{e}}$, J.F. Huanga,b,c, S. A . Wan $^{\mathrm{a}, \mathrm{b}}$, D. Bastviken ${ }^{\mathrm{f}}, \mathrm{C}$. Tong, $\mathrm{g}^{\mathrm{a}, \mathrm{b}, \mathrm{c}, *}$

${ }^{a}$ Key Laboratory of Humid Sub-tropical Eco-geographical Process of Ministry of Education of China, Fujian Normal University, Fuzhou, China

${ }^{\mathrm{b}}$ School of Geographical Sciences, Fujian Normal University, Fuzhou, China

${ }^{\mathrm{c}}$ Research Centre of Wetlands in Subtropical Region, Fujian Normal University, Fuzhou, China

${ }^{\mathrm{d}}$ Department of Geography and Resource Management, The Chinese University of Hong Kong, Shatin, New Territories, Hong Kong SAR, China

${ }^{\mathrm{e}}$ Department of Geography, Hong Kong Baptist University, Kowloon Tong, Hong Kong, China

${ }^{\mathrm{f} D e p a r t m e n t}$ of Thematic Studies - Environmental Change, Linköping University, Linköping, Sweden

*Correspondence: Chuan Tong

Phone: 086-0591-87445659 Email: tongch@fjnu.edu.cn Fax: 086-0591-83465397

*Correspondence: Derrick Y.F. Lai

Phone: 852-39436528 Email: dyflai@cuhk.edu.hk Fax: 852-26035006

\section{Supporting Information Summary}




\section{No. of pages: 12 No. of Figures: 6}

Page S3: Materials and Methods

Page S5: Fig. S1. Monthly precipitation in 2007-2009 and 2013-2014 for the Min River Estuary Station (mean represents the average for 2007-2009 and 2013-2014).

Page S6: Fig. S2. Regression and significance analysis between profiles of $\mathrm{CH}_{4}$ production rate $(y)$ and porewater $\mathrm{SO}_{4}{ }^{2-}$ concentration $(x)$ in the brackish $C$. malaccensis marsh for 2012.

Page S7: Fig. S3. Relationship between the average seasonal $\mathrm{CH}_{4}$ production rates at five depths and soil temperature in the brackish C. malaccensis marsh for 2012.

Page S8: Fig. S4. Relationship between seasonal mean $\mathrm{CH}_{4}$ emissions and soil $\mathrm{CH}_{4}$ production rate at different depths in the brackish C. malaccensis marsh.

Page S9: Fig. S5. Relationship between seasonal mean $\mathrm{CH}_{4}$ emissions and mean porewater $\mathrm{CH}_{4}$ concentration in the brackish $C$. malaccensis marsh.

Page S10: Fig. S6. Relationships between $\mathrm{CH}_{4}$ emissions and air temperature $\left({ }^{\circ} \mathrm{C}\right)$ or soil temperature at the surface soil $(0-25 \mathrm{~cm})$ in the brackish C. malaccensis marsh from 2007 to 2008 and 2013 to 2014, as described by the exponential function $(P<$ $0.05)$.

\section{Materials and Methods}

\section{Methane gas sampling and flux estimation}

The $\mathrm{CH}_{4}$ flux $\left(F, \mathrm{~mol} \mathrm{~m}^{-2} \mathrm{~h}^{-1}\right)$ was calculated according to the following equation (1):

$$
F=\frac{\mathrm{d} n}{\mathrm{~d} t} \times \frac{1}{A}
$$

where $\mathrm{d} n / \mathrm{d} t$ is the slope of amount of substance for $\mathrm{CH}_{4}$ over sampling period (mol $\left.\mathrm{h}^{-1}\right) ; A$ is the chamber area $\left(\mathrm{m}^{2}\right)$. The amount of $\mathrm{CH}_{4}$ in the chamber at different times was calculated from the following equation (2):

$$
n=p p m \times 10^{-6} \times \frac{P_{t o t} \times V}{R \times T}
$$


where $p p m$ is parts per million (usually comes from GC measurement); $P_{\text {tot }}$ is total air pressure (usually around $1 \mathrm{~atm}=1013.15 \mathrm{hPa}$ ); $V$ is the chamber volume $(\mathrm{L}) ; R$ is common gas constant $\left(0.082056 \mathrm{~L}\right.$ atm $\left.\mathrm{K}^{-1} \mathrm{~mol}^{-1}\right) ; T$ is the absolute temperature during sampling (K). In present study, the unit of $\mathrm{CH}_{4}$ flux was showed as $\mathrm{mg} \mathrm{m}^{-2} \mathrm{~h}^{-1}$ $\left(=F \times M \times 10^{3}\right), M$ is molar mass of $\mathrm{CH}_{4}\left(\mathrm{~g} \mathrm{~mol}^{-1}\right)$.

Collection and analysis of $\mathrm{SO}_{4}{ }^{2-}$ concentrations in porewater

To determine porewater $\mathrm{SO}_{4}{ }^{2-}$ concentrations across different soil depths, triplicate sediment cores down to $100 \mathrm{~cm}$ depth were collected in January (winter), March (spring), July (summer) and October (autumn) of 2012. The sediment cores were collected using a steel sediment samplers $(\Phi=5 \mathrm{~cm})$ and split into ten depths at $10 \mathrm{~cm}$ intervals. Soil samples were immediately placed into valve bag and sealed. These sediment samples were subsequently kept on ice in coolers, and transported to the laboratory within $6 \mathrm{~h}$. Upon return to the laboratory, porewater from each depth interval was extracted from the sediment by centrifugation $(5000 \mathrm{rpm}, 10 \mathrm{~min}$, Cence ${ }^{\circledR}$ L550) and then filtered $\left(0.45 \mu \mathrm{m}\right.$ acetate fibre membranes). Finally, the $\mathrm{SO}_{4}{ }^{2-}$ concentration was determined using the barium chromate colorimetric method. The incubation chambers equipped with the soil depth of 90 and $100 \mathrm{~cm}$ fall to the ground and damaged during the winter experimental period. Therefore, the soil $\mathrm{SO}_{4}{ }^{2-}$ concentration at 90 and $100 \mathrm{~cm}$ during the winter is not present in this study. 


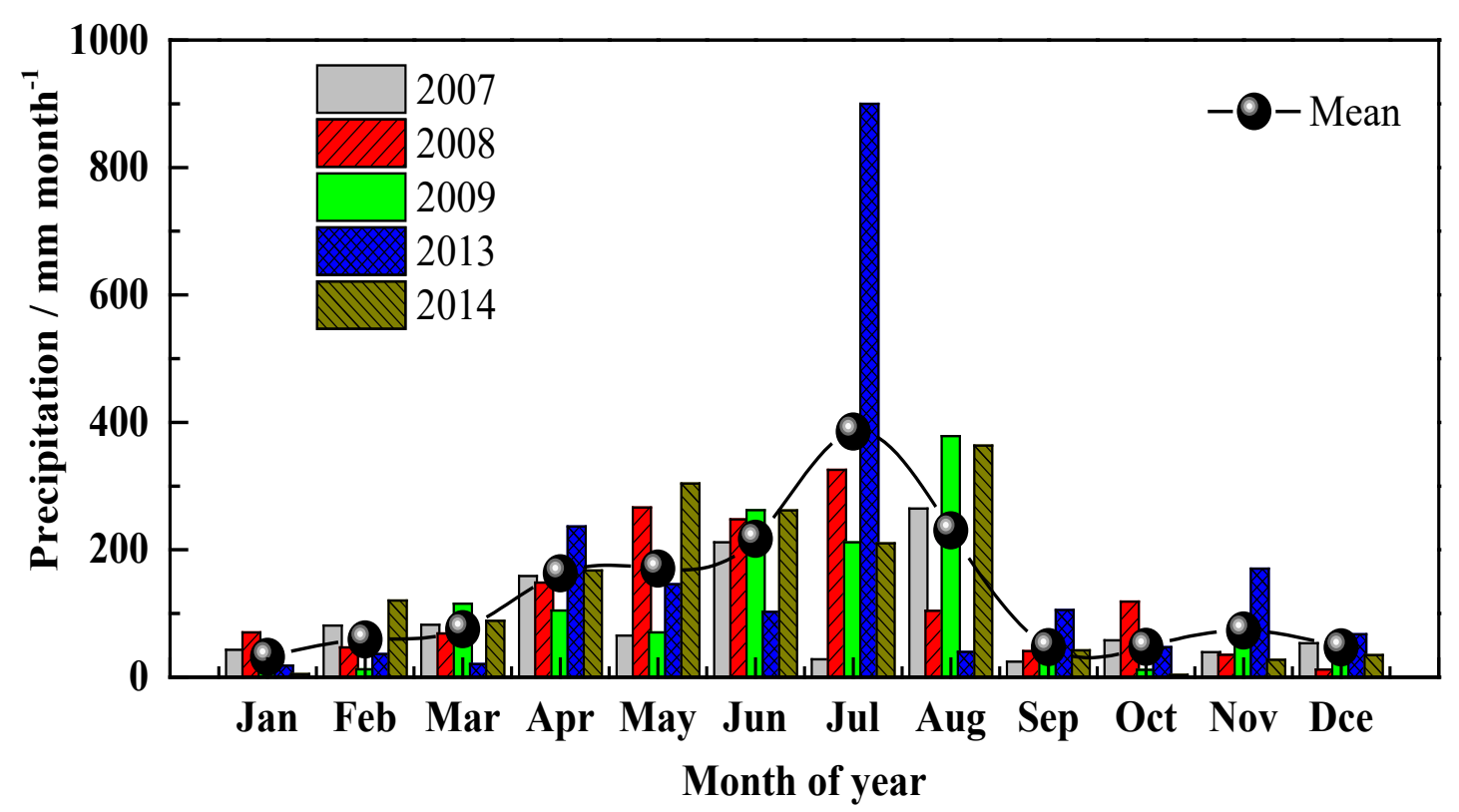

Fig. S1. Monthly precipitation in 2007-2009 and 2013-2014 for the Min River Estuary Station (mean represents the average for 2007-2009 and 2013-2014).
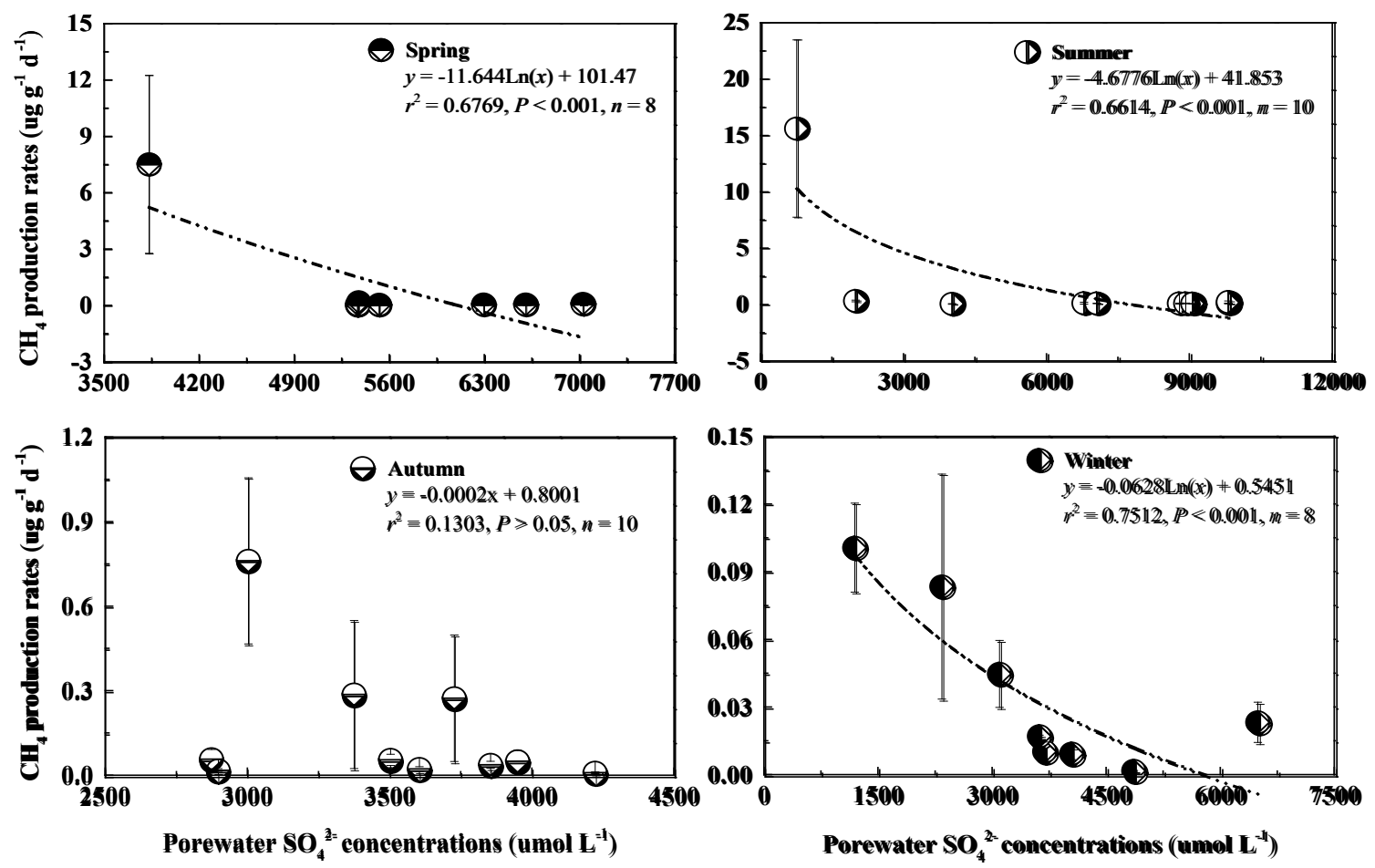

Fig. S2. Regression and significance analysis between profiles of $\mathrm{CH}_{4}$ production rate $(y)$ and porewater $\mathrm{SO}_{4}{ }^{2-}$ concentration $(x)$ in the brackish C. malaccensis marsh for 2012. The soil porewater $\mathrm{SO}_{4}{ }^{2-}$ concentrations during summer and autumn were for the depth of $0-100 \mathrm{~cm}(n=$ 10). The soil porewater $\mathrm{SO}_{4}{ }^{2-}$ concentrations during spring and winter were for the depth of $0-80$ $\mathrm{cm}(n=8) . \mathrm{CH}_{4}$ production rates and porewater $\mathrm{SO}_{4}{ }^{2-}$ concentrations in each soil depth were the averaged values of three sampling sites. 


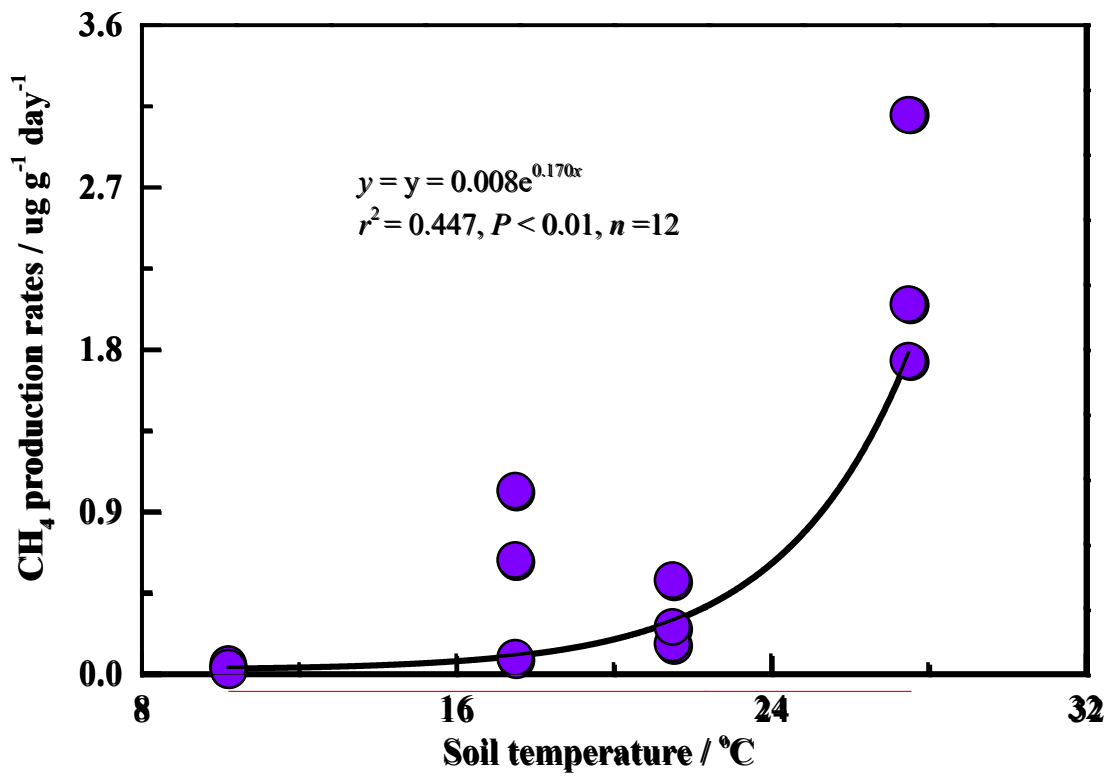

Fig. S3. Relationship between the average seasonal $\mathrm{CH}_{4}$ production rates at five depths and soil temperature in the brackish C. malaccensis marsh for 2012. 

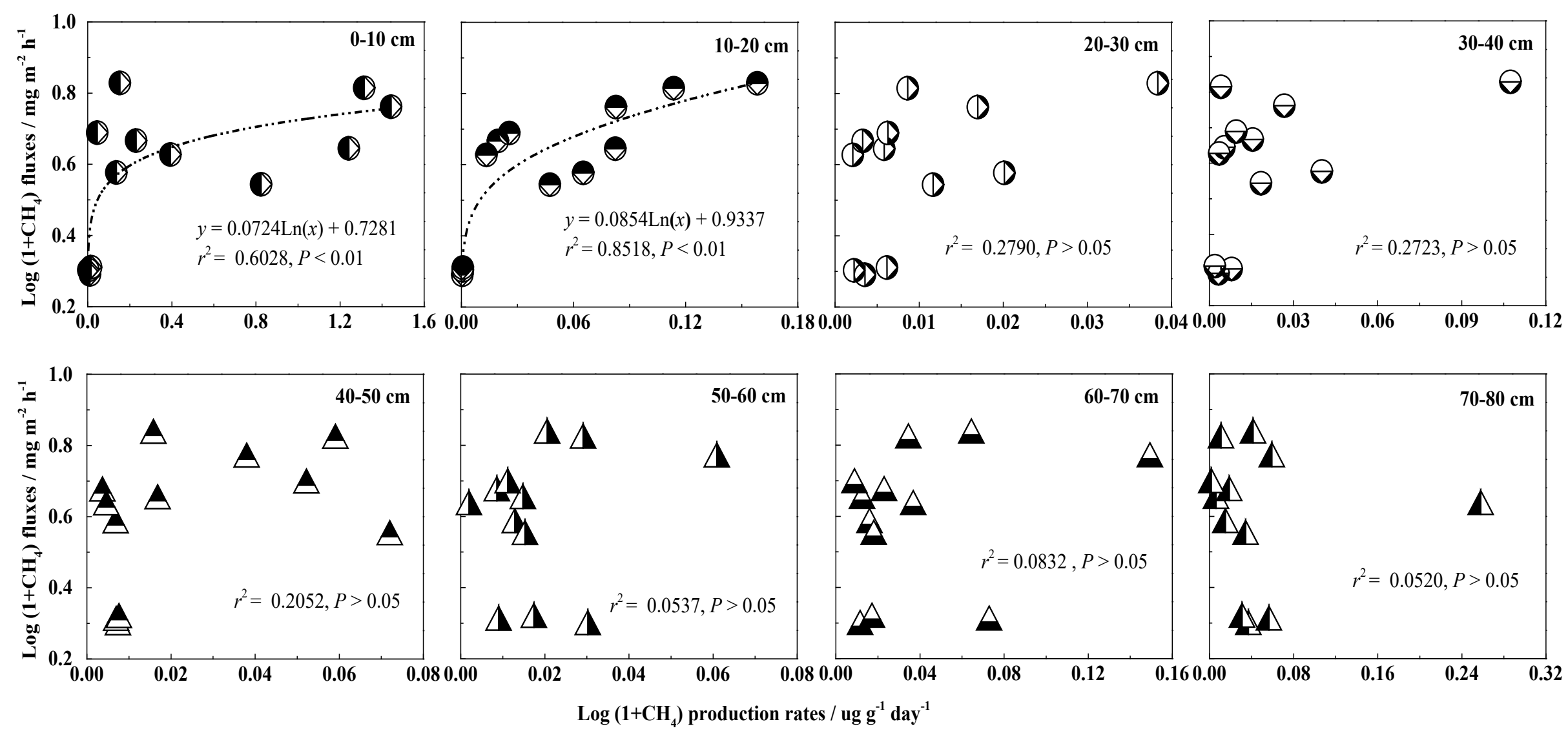

Fig. S4. Relationship between seasonal mean $\mathrm{CH}_{4}$ emissions and soil $\mathrm{CH}_{4}$ production rate at different depths in the brackish $C$. malaccensis marsh. 


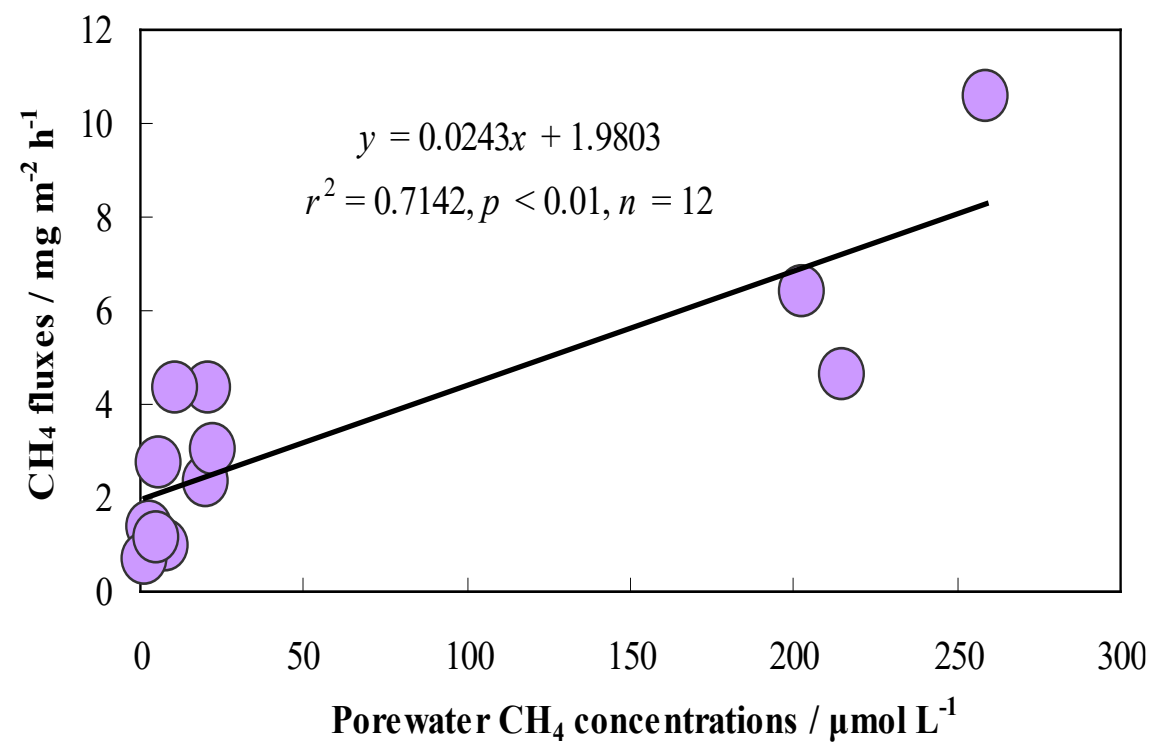

Fig. S5. Relationship between seasonal mean $\mathrm{CH}_{4}$ emissions and mean porewater $\mathrm{CH}_{4}$ concentration in the brackish $C$. malaccensis marsh for 2013. (12 samples $=1$ average value at five depths $\times 3$ sites $\times 4$ seasons $)$. 

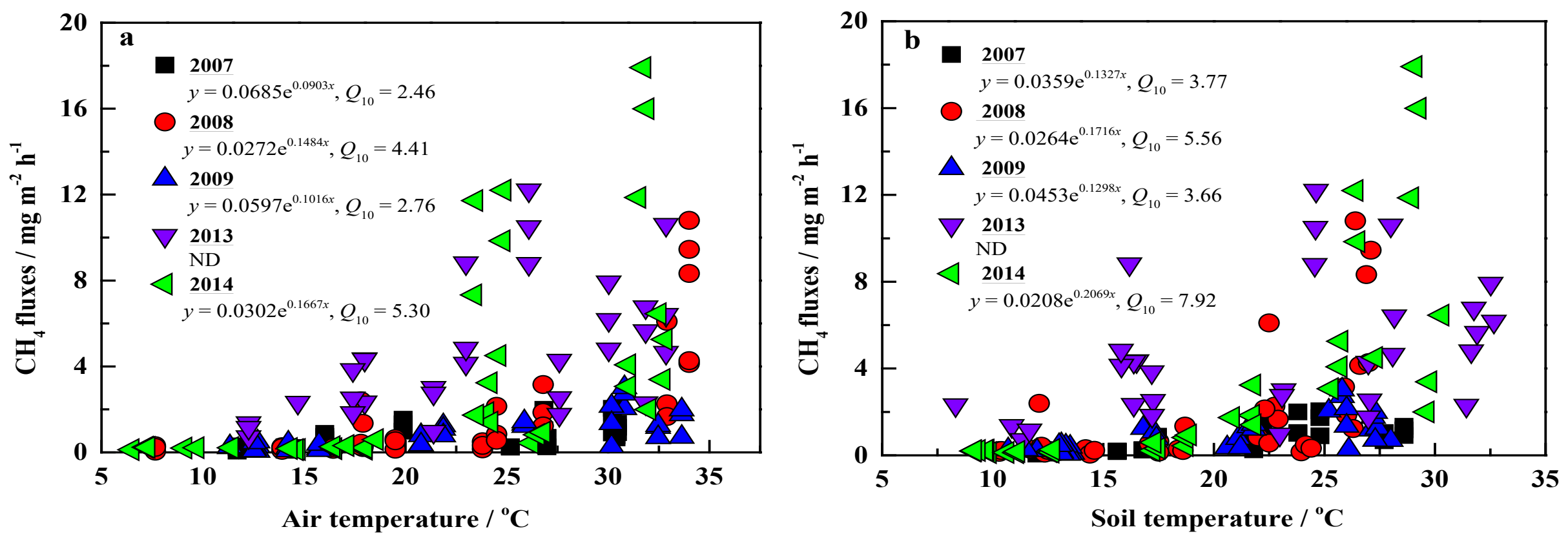

Fig. S6. Relationships between $\mathrm{CH}_{4}$ emissions and air temperature $\left({ }^{\circ} \mathrm{C}\right)$ or soil temperature at the surface soil $(0-25 \mathrm{~cm})$ in the brackish $C$. malaccensis marsh from 2007 to 2008 and 2013 to 2014 , as described by the exponential function $(P<0.05) . n=36$ for air temperature, soil temperature and $\mathrm{CH} 4 \mathrm{emissions}$ of each year. ND means "no significant relationship". 